\title{
Crescimento inicial da alface hidropônica sob diferentes níveis de salinidade em sistema automatizado com Arduino Uno em função da temperatura e umidade do ar no semiárido
}

Initial growth of hydroponics lettuce under different salinity levels in an automated system with Arduino Uno as a fuction of air temperature and humidity in the semiarid Crecimiento inicial de lechuga hidropónica bajo diferentes niveles de salinidad en un sistema automatizado con arduino uno en función de la temperatura y humedad del aire en el semiárido

Leoncio Gonçalves Rodrigues ORCID: https://orcid.org/0000-0002-8770-9172 Universidade Federal do Cariri, Brasil E-mail: leonmeid@gmail.com

Ana Célia Maia Meireles ORCID: https://orcid.org/0000-0002-8860-2043 Universidade Federal do Cariri, Brasil E-mail: ana.meireles@ufca.edu.br Carlos Wagner Oliveira ORCID: https://orcid.org/0000-0003-1013-2974 Universidade Federal do Cariri, Brasil E-mail: carlos.oliveira@ufca.edu.br

Lívia Soares Bernardo ORCID: https://orcid.org/0000-0003-0049-025X Universidade Federal do Cariri, Brasil E-mail: livia.soares@aluno.ufca.edu.br

Davi Hudson Pereira Simões ORCID: https://orcid.org/0000-0001-9600-4943 Universidade Federal do Cariri, Brasil E-mail: davi.simoes@aluno.ufca.edu.br

Antonio Hyago Mendes Gonçalves ORCID: https://orcid.org/0000-0002-5999-0913 Universidade Federal do Cariri, Brasil E-mail: carlos.oliveira@ufca.edu.br

\begin{abstract}
Resumo
O semiárido tem como principais características, baixa precipitação, secas recorrentes, altas temperaturas e baixas umidades do ar. Outro ponto, é que grande parte dos solos possui embasamento cristalino, conferindo qualidade inferior às águas subterrâneas. Nesse sentido, a irrigação, nem sempre é viável, por consequência dos recursos hídricos escassos. A hidroponia, no entanto, independe do solo e requer pouca água, às culturas cultivadas em hidroponia são mais tolerantes à salinidade, permitindo o uso de águas mais salinas. Diante do exposto, o objetivo desta pesquisa foi verificar o crescimento inicial da alface Crespa cv. Moana sob cultivo hidropônico no semiárido sob diferentes níveis de salinidade em um sistema automatizado com Arduino Uno, onde o intervalo de aplicação da solução opera em função da temperatura e umidade do ar. Para tanto, foram utilizados os níveis de salinidade 1,5, 2,0, 2,5, 3,0 e 3,5 dS m ${ }^{-1}$, em delineamento de blocos ao acaso com esquema fatorial de 5 x 5 no sistema do tipo Net Film Technique. Verificou-se que a automação em detrimento da temperatura e umidade promoveu uma maior economia de energia, a alface tem melhor desenvolvimento ao nível de $1,5 \mathrm{dS} \mathrm{m}^{-1}$. Portanto, o sistema de automação com Arduino é operacional além de permitir a associação de sensores, e que a alface cv. Moana para as condições do experimento não apresenta desenvolvimentismo inicial satisfatório acima de $2,0 \mathrm{dS} \mathrm{m}^{-1}$ devido aos efeitos deletérios da salinidade.
\end{abstract}

Palavras-chave: Tecnologia; Sensores; Produção; Inovação; Cultivo.

\section{Abstract}

The semiarid region has as main characteristics, low precipitation, recurrent droughts, high temperatures and low air humidity. Another point is that most of the soils have a crystalline basement, providing inferior quality to 
groundwater. In this sense, irrigation is not always viable, as a result of scarce water resources. Hydroponics, however, is soil-independent and requires little water, crops grown in hydroponics are more tolerant to salinity, allowing the use of more saline waters. Given the above, the objective of this research was to verify the initial growth of lettuce Crespa cv. Moana under hydroponic cultivation in the semiarid region under different salinity levels in an automated system with Arduino Uno, where the solution application interval operates as a function of air temperature and humidity. For this purpose, salinity levels $1.5,2.0,2.5,3.0$ and $3.5 \mathrm{dS} \mathrm{m}^{-1}$ were used, in a randomized block design with a 5 x 5 factorial scheme in the type system Net Film Technique. It was found that automation at the expense of temperature and humidity promoted greater energy savings, lettuce has better development at the level of $1.5 \mathrm{dS} \mathrm{m}^{-1}$. Therefore, the automation system with Arduino is operational in addition to allowing the association of sensors, and lettuce cv. Moana for the conditions of the experiment does not present satisfactory initial developmentalism above $2.0 \mathrm{dS} \mathrm{m}^{-1}$ due to the deleterious effects of salinity.

Keywords: Technology; Sensors; Production; Innovation; Cultivation.

\section{Resumen}

La región semiárida tiene como características principales, bajas precipitaciones, sequías recurrentes, altas temperaturas y baja humedad del aire. Otro punto es que la mayoría de los suelos tienen un basamento cristalino, lo que proporciona una calidad inferior a las aguas subterráneas. En este sentido, el riego no siempre es viable, como consecuencia de la escasez de recursos hídricos. La hidroponía, sin embargo, es independiente del suelo y requiere poca agua, los cultivos que se cultivan en hidroponía son más tolerantes a la salinidad, lo que permite el uso de aguas más salinas. Dado lo anterior, el objetivo de esta investigación fue verificar el crecimiento inicial de la lechuga Crespa cv. Moana bajo cultivo hidropónico en la región semiárida bajo diferentes niveles de salinidad en un sistema automatizado con Arduino Uno, donde el intervalo de aplicación de la solución opera en función de la temperatura y humedad del aire. Para ello se utilizaron niveles de salinidad 1.5, 2.0, 2.5, 3.0 y 3.5 dS m-1, en un diseño de bloques al azar con un esquema factorial 5 x 5 en el sistema tipo Net Film Technique. Se encontró que la automatización a expensas de la temperatura y la humedad promovió un mayor ahorro de energía, la lechuga tiene un mejor desarrollo al nivel de $1.5 \mathrm{dS}$ m-1. Por tanto, el sistema de automatización con Arduino está operativo además de permitir la asociación de sensores y cv de lechuga. Moana para las condiciones del experimento no presenta un desarrollismo inicial satisfactorio por encima de $2.0 \mathrm{dS}$ m-1 debido a los efectos deletéreos de la salinidade.

Palabras clave: Tecnología; Sensores; Producción; Innovación; Cultivo.

\section{Introdução}

O semiárido tem como principal característica o balanço hídrico deficitário durante o ano, com altas temperaturas, baixas umidades e altas taxas de evapotranspiração, principalmente nos meses mais secos. Segundo Ximenes, Silva e Brito (2019) a temperatura anual é estável com média entre 24 e $26{ }^{\circ} \mathrm{C}$ e a umidade relativa do ar varia entre $54,5 \%$ a $86,4 \%$. Os índices pluviométricos oscilam de 500 a $850 \mathrm{~mm}$ ao ano, com mais de $70 \%$ das chuvas concentrando-se em um pequeno espaço de tempo, geralmente nos primeiros quatro meses de janeiro, fevereiro, março e abril. Por outro lado, a evapotranspiração anual oscila entre 2100 e 2600 mm, o que exige o armazenamento de água para ser utilizada nos meses de seca (Araújo, 2012).

Outro ponto, é que seu subsolo tem como origem de rochas pré-cambrianas em cerca de 50\%, essas rochas constituem o embasamento cristalino que ocupa $70 \%$ da região, em que as águas subterrâneas são armazenadas em rochas fissuradas, reduzindo sua quantidade e qualidade (Gama \& Jesus, 2019). A fonte de água, que tem sua origem em rochas fissuradas, costuma apresentar baixas vazões em torno de dois a cinco metros cúbicos por hora (Costa Filho, Galvão, Lima \& Leal, 1998). De acordo com Brito et al., (2009) a predominância de solos cristalinos no semiárido implicam em águas com salinidade superior ao normal, atribuindo maior risco de degradação do solo.

Além dessas condições adversas, os solos superficiais são difíceis para a atividade agrícola. Segundo Gama e Jesus (2019) o semiárido tem como principais classe de solos, os neossolos, latossolos e luvissolos. Que são solos de difícil manejo, o que torna a atividade agrícola um grande desafio. Quando os solos são adequados para o cultivo, a irrigação costuma ser empregada onde há fonte de água disponível em quantidade e qualidade, caso contrário as lavouras são cultivadas na época das chuvas. 
Por outro lado, se analisarmos o sistema hidropônico de produção perceberemos que algumas limitações de solo e água encontradas em sistemas convencionais ou irrigados no semiárido, não estão presentes para este. No cultivo sem solo, algumas águas consideradas inadequadas para outras formas de cultivo podem ser utilizadas com sucesso (Paulus, 2008; Bezerra Neto, 2017).

Desse modo, a hidroponia pode ser uma alternativa ao cultivo agrícola convencional, com a vantagem de garantir uma produção de maior qualidade, em um menor espaço, com menos água e sem uso de solo, viabilizando a geração de renda e a preservação do meio ambiente, além de ser um sistema mais sustentável (Dias, 2019).

Para Soares et al. (2007) é possível utilizar águas salinas para a produção de alface em cultivo hidropônico, sendo uma alternativa interessante a ser explorada no semiárido, diante das dificuldades climáticas, hídricas e de solo, viabilizando assim, a utilização de águas de qualidade inferior até então sem aplicações, o que favorece o crescimento e desenvolvimento regional sustentável. A hidroponia é uma técnica bastante versátil, principalmente para locais onde não se dispõe de condições necessárias para o cultivo convencional, podendo ser adaptada e flexibilizada para diversas condições e culturas (Paulus, 2008; Bezerra Neto, 2017; Dias, 2019).

A região semiárida apresenta condições que permitem a exploração hidropônica da cultura da alface durante o ano todo, todavia a maior parte do cultivo desta hortaliça advém de sistemas de cultivo convencionais em solo (Bezerra Neto, 2017). Instigar a utilização da hidroponia por pequenos produtores, permitirá a criação de uma alternativa econômica de cultivo agrícola sustentável, em locais onde o solo ou água são fatores limitantes no semiárido. Portanto, é necessário desenvolver tecnologias que permitam a flexibilização e o alcance deste conhecimento para esses produtores.

Posto isto, esta pesquisa buscou avaliar o crescimento inicial da alface crespa cv. Moana sob diferentes níveis de salinidade da solução (1,5, 2,0, 2,5, 3,0 e 3,5 $\mathrm{dS} \mathrm{m}^{-1}$ ) em um sistema hidropônico NFT (Nutrient Film Technique) de baixo custo e automatizado com Arduino em detrimento da mudança de temperatura e umidade do ar. É desse modo, apresenta uma alternativa de automação para cultivo hidropônico no semiárido que opera em detrimento da alteração da temperatura e umidade do ar, assim como avaliar os níveis de salinidade máximos que permitam o cultivo hidropônico da alface na região.

\section{Metodologia}

O projeto foi desenvolvido na Universidade Federal do Cariri (UFCA), campus Crato-CE, no período de 18 de outubro de 2021 a 16 de dezembro de 2021 , em uma área experimental localizada na latitude $-7^{\circ} 13$ ' $48^{\prime \prime} \mathrm{S}$ e longitude $-39^{\circ}$ 21' 36" W. De acordo com a classificação climática de Köppen-Geiger o clima da região é B1 W2A 'a' com temperatura média anual de $25,10{ }^{\circ} \mathrm{C}$ e precipitação média anual de $1086 \mathrm{~mm}$, com precipitação concentrando de janeiro a maio (Lima et al., 2017).

Para a condução do experimento confeccionou-se três bancadas B1, B2 e B3 com sistema do tipo Nutrient Film Technique (NFT) instalados dentro de um viveiro de dimensões 4,00 x 10,00 x 2,00 m de largura, comprimento e altura, cercado com uma tela de sombreamento com fator de retenção de 50\%. As bancadas foram dimensionadas com 2,00 m x 3,00 $\mathrm{m}$ de largura e comprimento, o suporte dos canais foi confeccionado de madeira.

Cada bancada possui cinco canais espaçados em $0,30 \mathrm{~m}$, confeccionados com tubos de PVC ("linha de esgoto reciclável") com comprimento de 3,00 m, com seção interna de $\varnothing 0,075 \mathrm{~m}$, onde foram feitas perfurações com $\varnothing 0,05 \mathrm{~m}$ espaçadas em 0,25 m para disposição da cultura. Portanto, perfazendo a capacidade de 50 plantas para cada bancada, onde cada canal comporta 10 plantas em seu respectivo tratamento. A declinação dos canais utilizados foi de $3 \%$.

Para tubulação de distribuição da solução nutritiva foi utilizado uma mangueira de PVC com diâmetro interno de 0,02 $\mathrm{m}$, saindo dos recipientes até os blocos e seus respectivos tratamentos. A derivação da distribuição para as calhas foi realizada 
com mangueira tipo espaguete com diâmetro $0,006 \mathrm{~m}$. No bombeamento da solução nutritiva foram utilizadas 5 bombas automáticas de 12v com vazão de 6,00 litros por minuto, compartilhadas entre os blocos e seus respectivos tratamentos.

A alface utilizada foi do tipo Crespa, cultivar Moana, da empresa ISLA, cujas principais características são tamanho médio, cor verde claro e tolerância ao tipo Burn (deficiência de cálcio). A alface foi submetida a diferentes níveis de salinidade 1,5; 2,0, 2,5, 3,0; 3,5 dS m-1, que correspondem aos tratamentos A, B, C, D e E. O controle do pH e CE da solução foi realizado com o auxílio de medidor de condutividade elétrica portátil e medidor de $\mathrm{pH}$ da Analytical Instruments modelo EC3587, que foi devidamente calibrado em laboratório.

A formulação de solução nutritiva utilizada foi a proposta por Furlani (1998) que é comumente utilizada para o cultivo de folhosas. A Tabela 1 apresenta a quantidade de nutrientes para preparo de $1000 \mathrm{~L}$ de solução nutritiva para cultivo hidropônico de acordo com (Furlani, 1998).

Tabela 1. Quantidade de nutrientes para preparo de 1000 L de solução nutritiva para cultivo hidropônico.

\begin{tabular}{|c|c|c|c|c|}
\hline \multirow[t]{2}{*}{ Fertilizante } & \multirow[t]{2}{*}{1000 L de água } & \multicolumn{2}{|r|}{ Elementos } & \multirow[t]{2}{*}{ Recomendação } \\
\hline & & & $\mathrm{g}$ & \\
\hline \multirow[t]{3}{*}{ Nitrato de Cálcio } & 750 & $\mathrm{NH}_{4}$ & 7,5 & 24 \\
\hline & & $\mathrm{NO}_{3}$ & 108,75 & 173,75 \\
\hline & & $\mathrm{Ca}$ & 142,5 & 142,5 \\
\hline \multirow[t]{2}{*}{ Nitrato de potássio } & 500 & $\mathrm{NO}_{3}$ & 65 & - \\
\hline & & $\mathrm{K}$ & 182,5 & 182,5 \\
\hline \multirow[t]{2}{*}{ Fosfato monoamônio } & 150 & $\mathrm{NH}_{4}$ & 16,5 & - \\
\hline & & $\mathrm{P}$ & 39 & 39 \\
\hline \multirow[t]{2}{*}{ Sulfato de magnésio } & 400 & $\mathrm{Mg}$ & 40 & 40 \\
\hline & & $\mathrm{S}$ & 52 & 52 \\
\hline Sulfato de cobre & 0,15 & $\mathrm{Cu}$ & 0,02 & 0,02 \\
\hline Sulfato de zinco & 0,5 & $\mathrm{Zu}$ & 0,07 & 0,07 \\
\hline Sulfato de manganês & 1,5 & $\mathrm{Mn}$ & 0,39 & 0,39 \\
\hline Ácido bórico ou & 1,8 & B & 0,31 & 0,31 \\
\hline Molibdato de sódio & 0,15 & Mo & 0,06 & 0,06 \\
\hline Fe-EDTA $-13 \% \mathrm{Fe}$ & 13,8 & $\mathrm{Fe}$ & 2,08 & 2,08 \\
\hline Total & 1817,9 & & 656,68 & 656,68 \\
\hline
\end{tabular}

Fonte: Furlani (1998).

Os intervalos de aplicação da solução operaram em função da temperatura e umidade do ar. No Quadro 1 é apresentada as Equações da 1 a 5 com as estruturas condicionais utilizadas A Equação 1 verifica o estado "dia" ou "noite", as Equações 2 e 3 são direcionadas quando o estado da Equação 1 é "dia", e as Equações 4 e 5 "noite". Figura 1 apresenta o fluxograma da estrutura condicional do sistema de automação, onde deve-se atentar aos direcionamentos de fluxos que são promovidos pelas equações. 
Quadro 1. Resumo da estrutura condicional empregada no sistema de automação.

\begin{tabular}{|c|c|c|c|}
\hline \multicolumn{2}{|c|}{ Tempo (min) } & \multirow{2}{*}{ Equações } & \\
\hline Ligado & Desligado & & \\
\hline- & - & if $(\mathrm{LDR}==\mathrm{LOW})\{\mathrm{ID}\}$ else $\{\mathrm{IN}\}$ & (1) \\
\hline 15 & 10 & if $($ Temp $>=32$ or Umid $<=45)\{$ ID $\}$ & (2) \\
\hline 15 & 15 & else if (Temp $<32$ or Umid $>45)\{$ ID $\}$ & (3) \\
\hline 15 & 60 & if $($ Temp $>=32$ or Umid $<=45)\{$ IN $\}$ & (4) \\
\hline 15 & 120 & else if $($ Temp $<32$ or Umid $>45)\{$ IN $\}$ & (5) \\
\hline
\end{tabular}

Fonte: Autores.

Figura 1. Fluxograma da estrutura condicional do código de automação do sistema.

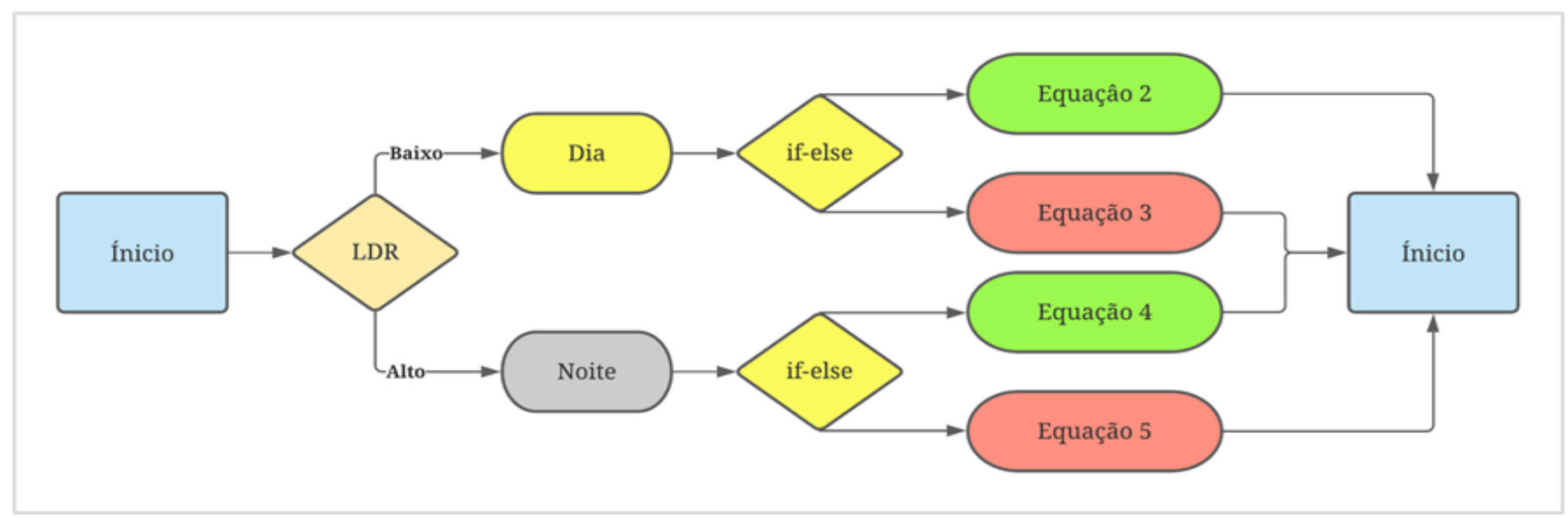

Fonte: Autores.

Em que: if: instrução "se" verifica se a primeira condição seja verdadeira, nesse caso executa linhas de código; else: instrução "então", caso a primeira instrução não seja verdadeira executa linhas de código; else if: instrução "então se" caso a primeira condição não seja verdadeira verificar segunda condição, se for verdadeira executar linhas de código; LDR: estado do sensor LDR , onde LOW é o estado "dia” e HIGH "noite"; ID: Instruções a serem executadas durante o dia; IN: Instruções a serem executadas durante a noite; Temp: Temperatura do ar no momento; Umid: Umidade relativa do ar no momento; Or: operador relacional OR “ou”.

Desse modo, as equações do Quadro 1 estão representadas através da estrutura condicional expressa no fluxograma da Figura 1, sendo um resumo da codificação em linguagem de programação $\mathrm{C}++$ desenvolvida para o sistema de automação na Arduino Integrated Development Environment (IDE).

Para montagem do sistema de automação foram utilizados o sensor de temperatura e umidade do ar DHT11, o sensor resistivo LDR para leitura da incidência de luz, um módulo de cartão de memória, dois módulos relês, uma matriz de contato e um Arduino Uno R3. Dados de temperatura e umidade do ar da estação da UFCA, distante cerca de 100,00m, também foram coletados para fins de comparação. A Figura 2 apresenta o diagrama de instalação dos componentes de automação. 
Figura 2. Diagrama de instalação dos componentes de automação.

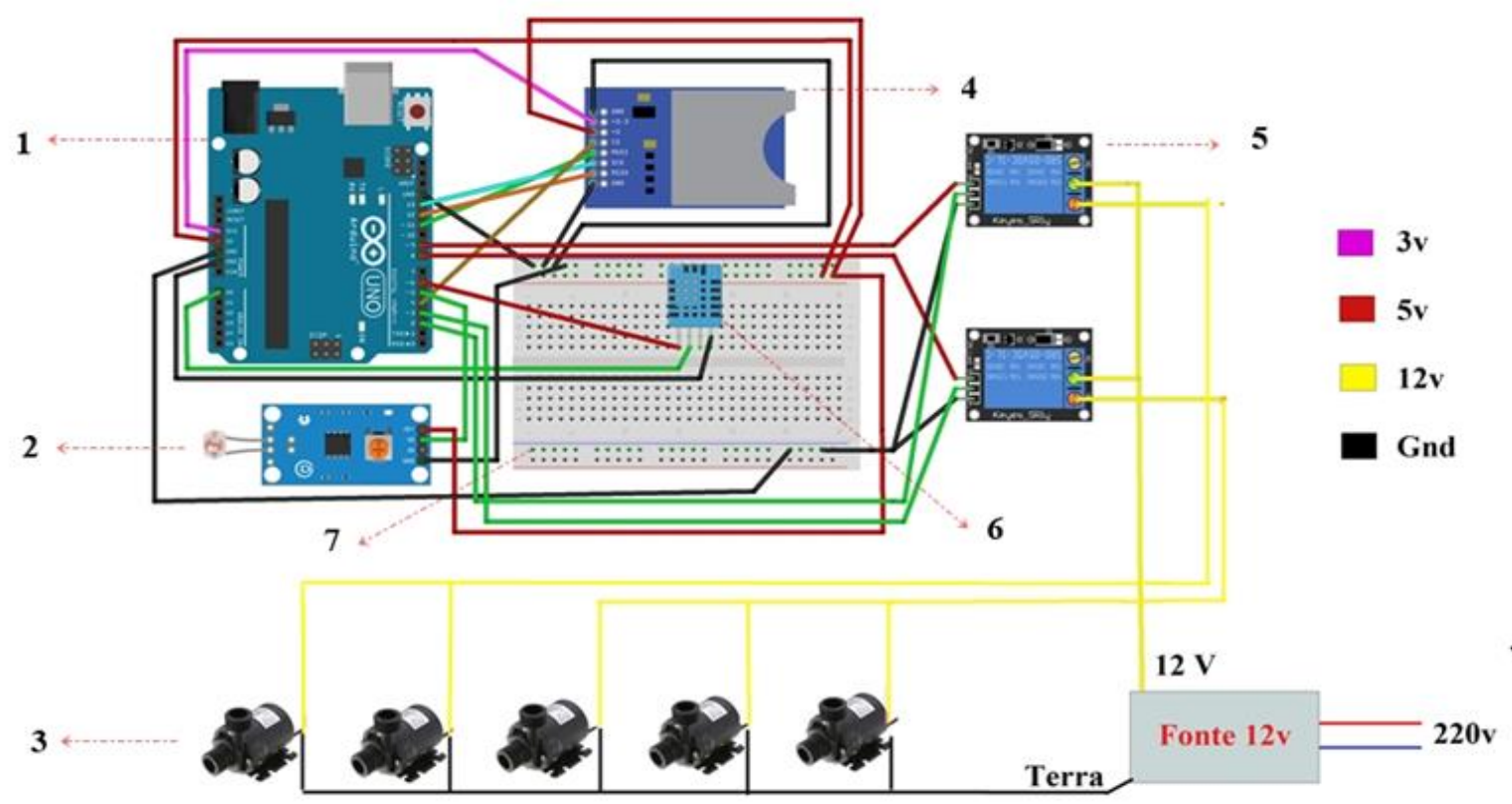
1 - Arduino Uno R3
3 - Bomba $12 \mathrm{v}$
5 - Módulo Relê
7 - Protoboard
2 - Módulo LDR
4 - Módulo SD
6 - Sensor DHT11

Fonte: Autores.

Na Figura 2, observa-se que todos os componentes estão ligados em uma matriz de contato (7), e que as bombas(3) são alimentadas por fonte externa de energia através de uma fonte chaveada de 12v 10A 120W bivolt, pelo fato do Arduino Uno (1) possuir uma tensão máxima em suas portas de 5v, sendo esta utilizada para o acionamento dos relês (5) que ligam as bombas, quando ocorre variação da temperatura e umidade identificada pelo sensor DHT11 (6), após verificado o estado de dia ou noite (2) e transcorrido os tempos de funcionamento e intervalos, as informações são armazenadas em uma unidade de memória (4).

As bancadas B1, B2, B3, foram divididas nos BL1, BL2, BL3, BL4 e BL5, cada uma com cinco tratamentos (A, B, C, D e E), para cada tratamento foram realizadas quatro repetições. O delineamento experimental utilizado foi blocos ao acaso (DBC). Segundo Santos e Gheyi (2003) em condições de campo o DBC é o delineamento mais empregado, em que sua eficiência depende da uniformidade e homogeneidade de cada bloco.

Foram avaliados os parâmetros morfológicos número de folhas (NF), diâmetro caulinar (DC), massa fresca das folhas (MFF), massa fresca das raízes (MFR) e a massa fresca total (MFT). Além desses, foram avaliados a vazão dos canais (AVC), a variação diária do pH, CE e a temperatura da solução nutritiva (TSN), a temperatura do ar (T), a umidade do ar (UR), intervalo de aplicação da solução (INT), consumo de energia (CK), temperatura máxima do ar da estação UFCA (TMAX), temperatura mínima do ar da estação UFCA (TMIN) e umidade relativa do ar estação UFCA (UMIN).

Para análise dos dados foi utilizado a Microsoft Office Excel, o software RStudio e R versão x64 4.0. e o software Sisvar versão 5.8 ao qual foi empregado o delineamento em blocos casualizados (DBC) em esquema fatorial 5 x 5 para as variáveis NF, MFF, MFR e MFT. 


\section{Resultados e Discussão}

O escoamento da solução nutritiva é crucial para garantir suprimento nutricional e hídrico adequado para o desenvolvimento das culturas. Furlani et al., (1999) estabelece que para o cultivo hidropônico da alface em sistema NFT devese utilizar uma vazão entre 1 a $2 \mathrm{~L} \mathrm{~min}^{-1}$ dependendo da fase vegetativa. Paulus (2008) do mesmo modo em cultivo alface hidropônico com águas salinas e estabelece uma vazão entre 1,5 a $2 \mathrm{~L} \mathrm{~min}^{-1}$. Tal qual Blat, Sanchez, Araújo e Bolonhezi (2011) que adotou uma vazão de $1,5 \mathrm{~L} \mathrm{~min}^{-1}$ para cultivo de alface crespa.

A vazão média dos tratamentos T1, T2, T3, T4 e T5 foi de 1,47; 1,61; 1,53;1,41 e 1,57 L. min ${ }^{-1}$ respectivamente, a vazão média para as bancadas B1, B2 e B3 foram 1,52; 1,48 e 1,54 $\mathrm{L} \mathrm{min}^{-1}$ e a vazão média do sistema como um todo de 1,52 $\mathrm{L} \min ^{-1}$. O Gráfico 1 apresenta a variação das vazões em cada tratamento nas bancadas.

Gráfico 1. Vazão média para as bancadas e tratamentos.

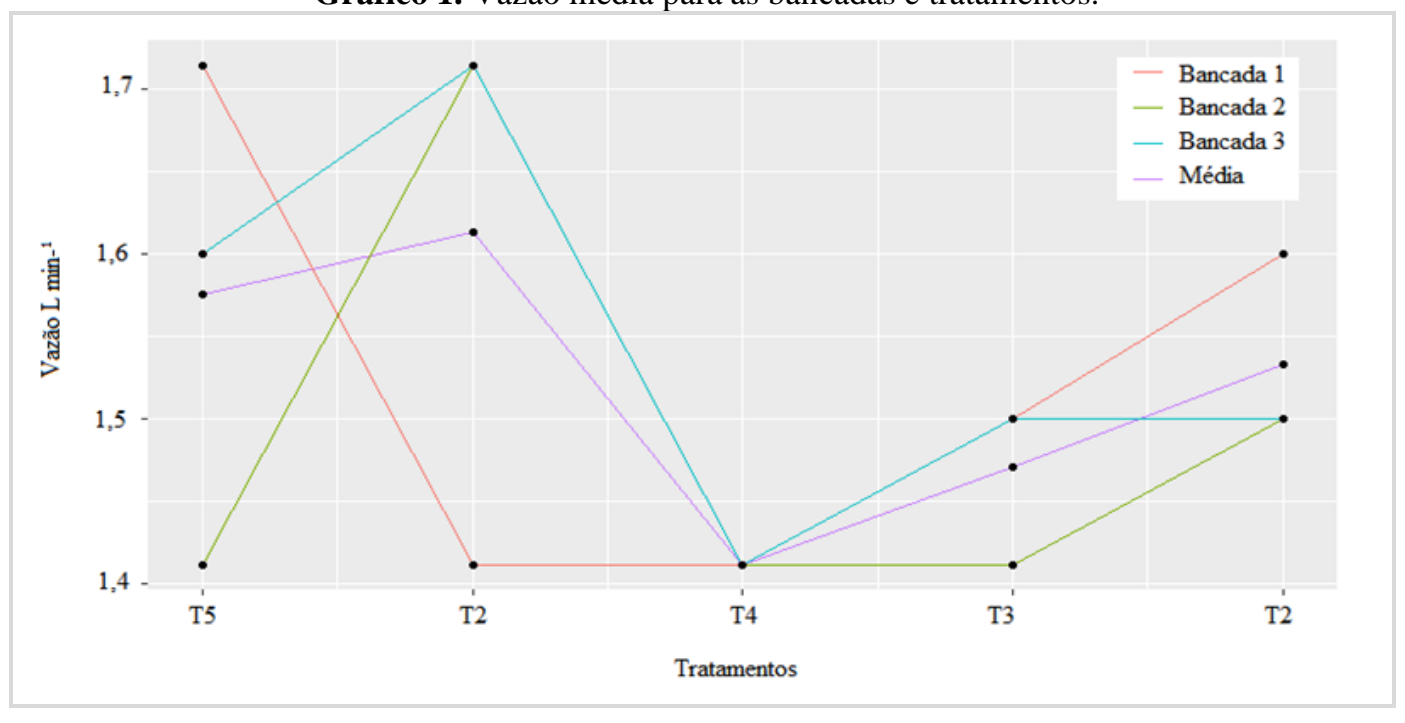

Fonte: Autores.

Ainda no Gráfico 1, verifica-se que a vazão varia entre os tratamentos, isso ocorre, por que existe perda de carga para os condutos que levam a solução, sendo muito difícil fazer com que cada calha receba exatamente a mesma quantidade de solução, entretanto os valores estão dentro de um limite desejável. Bernardo, Mantovani, Silva e Soares (2019) relata que a perda de carga ocorre em detrimento do atrito da água com as paredes de um tubo, aspectos como diâmetro, conexões, variação de nível entre outros, reduzem a pressão e consequentemente a vazão. O coeficiente de variação para as vazões foi de 8,28 \% com uma vazão média de $1,52 \mathrm{~L} \mathrm{~min}^{-1}$.

O sistema de automação com Arduino demonstrou-se funcional para circulação da solução nutritiva, não apresentando problemas em seu funcionamento para a programação especificada. Júnior et al., (2020) também encontraram viabilidade na automação de horta hidropônica utilizando sensores e Arduino. No Gráfico 2 é possível observar a variação dos intervalos de circulação da solução nutritiva em função da temperatura e umidade do ar como especificado na programação. 
Gráfico 2. Variação dos intervalos de circulação da solução nutritiva em função da temperatura e umidade do ar do dia 11 ao dia 29 de novembro de 2021 .

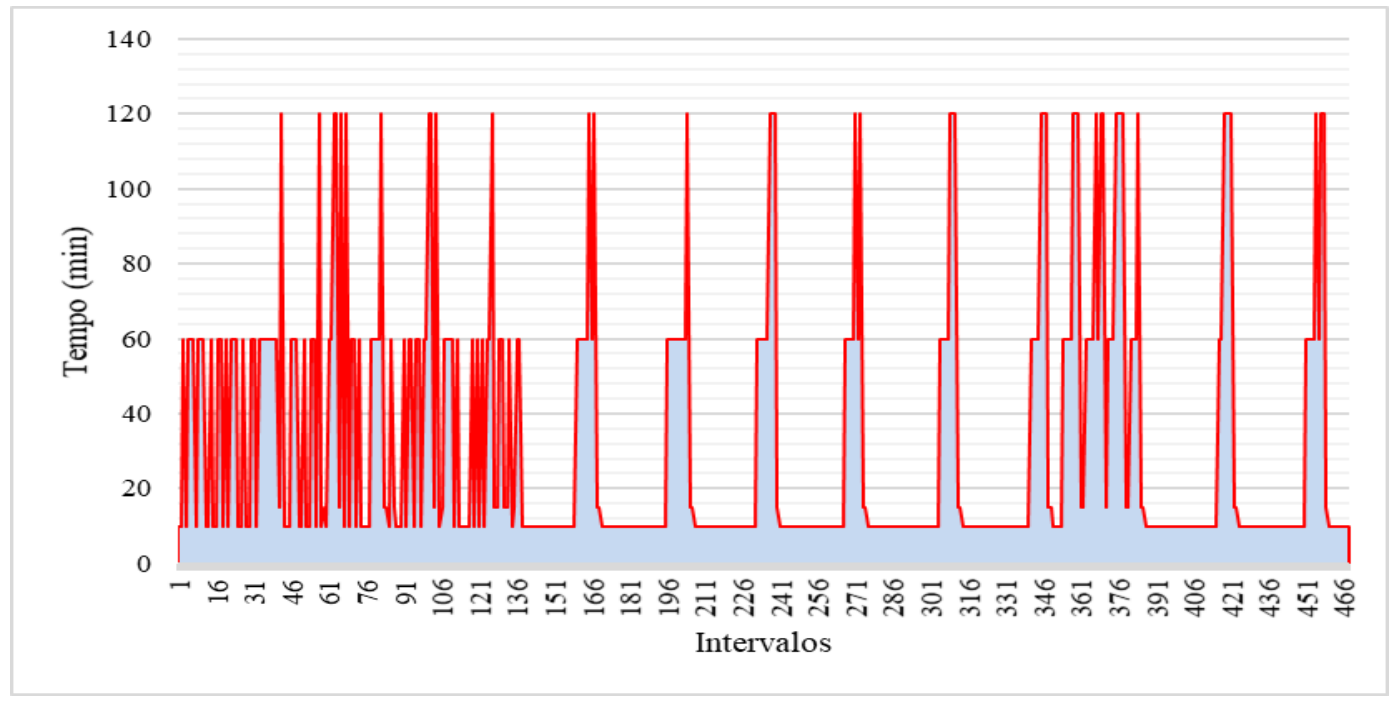

Fonte: Autores.

Os intervalos como estipulados na fase de codificação operaram sob as condições de variação da luz, temperatura e umidade. O que resultou na combinação de diferentes ciclos como apresentando. Constata-se que nos primeiros intervalos há uma maior predominância para o intervalo de $60 \mathrm{~min} \mathrm{"Ver} \mathrm{Gráfico} \mathrm{2",} \mathrm{pelo} \mathrm{fato} \mathrm{que} \mathrm{neste} \mathrm{período} \mathrm{ocorreu} \mathrm{leves} \mathrm{precipitações}$ como pode ser observado no Gráfico 3, que contribuem para o aumento de nuvens, redução da temperatura e elevação da umidade, tornando o clima ameno e reduzindo a indecência de luz sobre o sensor LDR. Mas, após o intervalo 136, os dias tornaram-se mais quentes e os intervalos passaram a ser de 10 minutos, seguidos de intervalos de 60 e 120 min durante a noite. O sensor LDR foi empregado para verificar se o momento é dia ou noite, mas este também pode ser utilizado para verificar a intensidade luminosa, como demonstrado por Domingos (2019) em cultivo hidropônico. Baron et al., (2021) relata que ocorre uma suavização no acionamento da recirculação da solução quando se utiliza intervalos variáveis.

Gráfico 3. Precipitações de 11 de novembro a 30 de novembro de 2021 para a estação da UFCA.

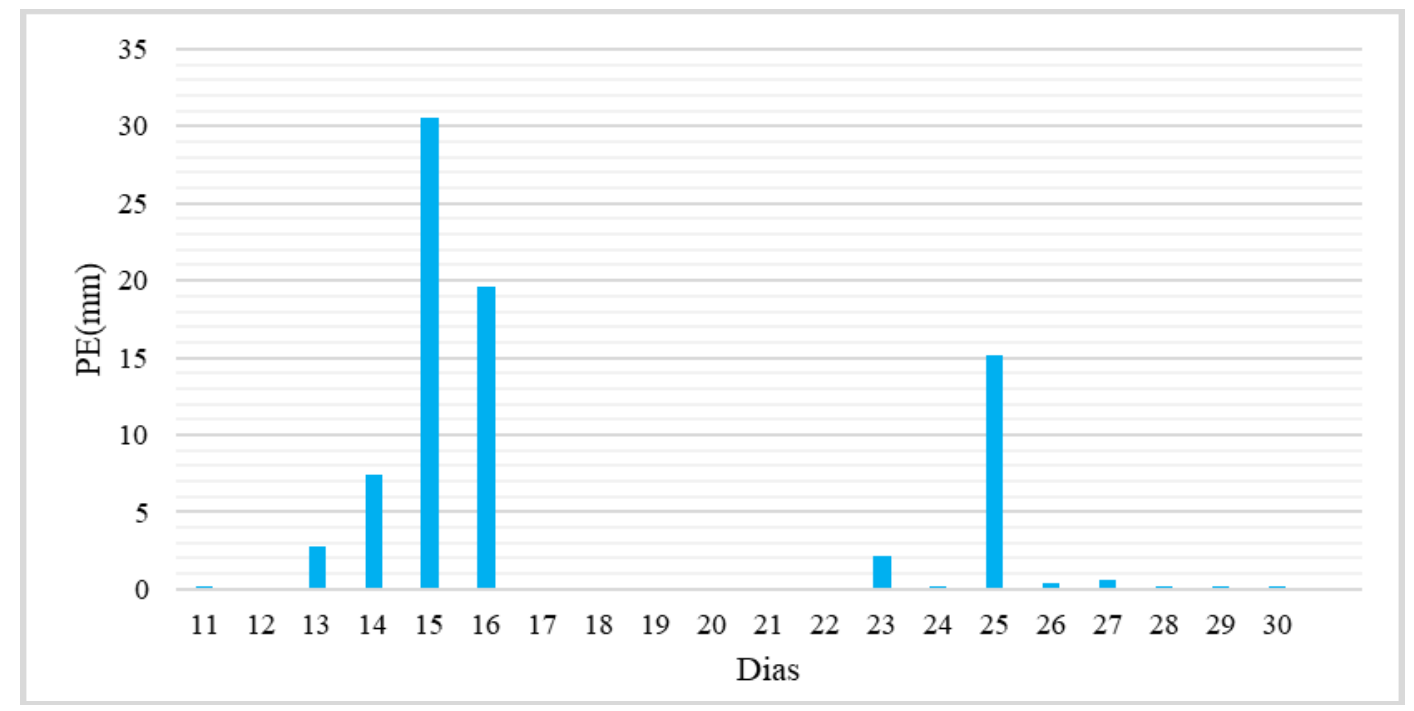

Fonte: Autores. 
O consumo total de energia em $\mathrm{Kw}$ foi de $11,12 \mathrm{Kw}$ para todos os tratamentos. Caso o sistema operasse de forma tradicional com intervalos de 15 minutos durante o dia e 2 horas a noite, o consumo total passaria a ser de 13,74 Kw, uma redução de $23,63 \%$ no consumo. Outro ponto é que houve uma redução mesmo havendo uma maior quantidade de intervalos de 10 minutos 274 vezes, conforme pode ser observado no Gráfico 4 que apresenta o consumo de energia das cinco bombas de 12 volts com potência de $19 \mathrm{~W}$ e vazão de $800 \mathrm{~L} \mathrm{~h}^{-1}$.

Gráfico 4. Consumo de energia (CK) em Kwh de 5 bombas de 12v com potência de $19 \mathrm{~W}$ e vazão de 800 L.h $h^{-1}$ e número de acionamentos por intervalo de tempo em minuto.

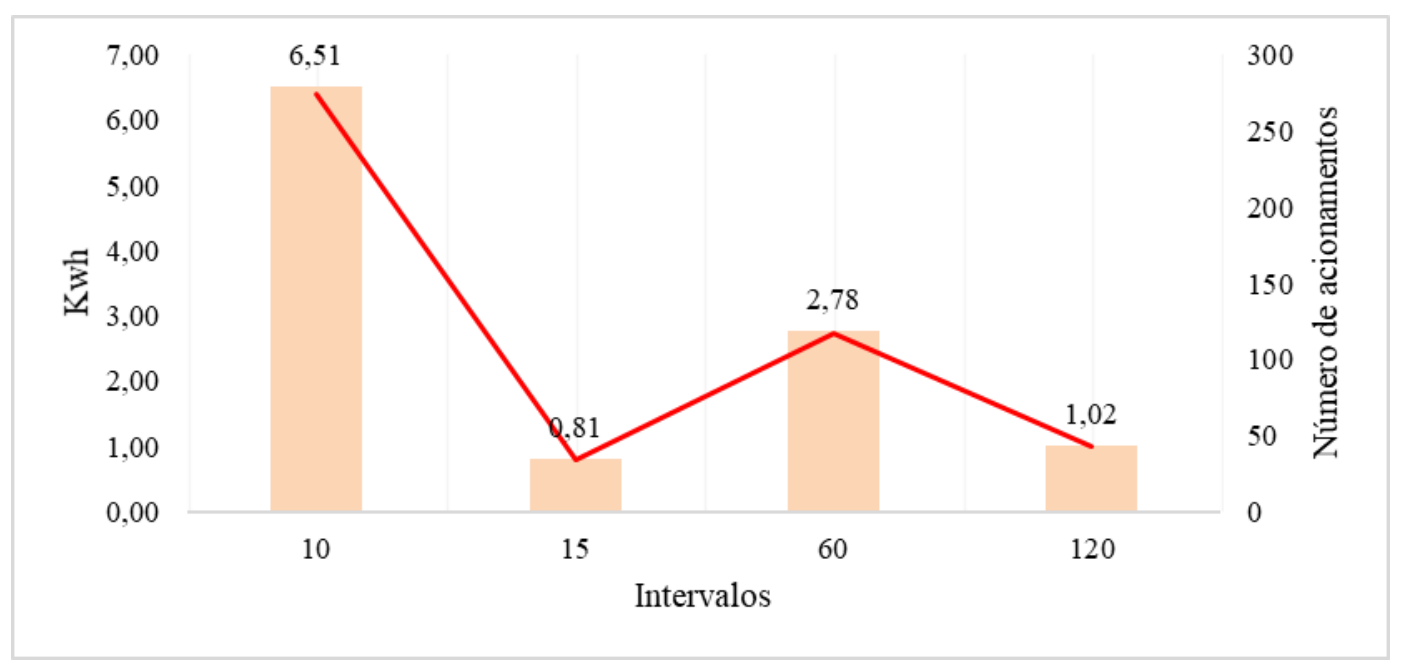

Fonte: Autores.

Ressalta-se que a economia é proporcional a potência da bomba e seu rendimento, para as bombas utilizadas de tensão de $12 \mathrm{v}$ e potência de $19 \mathrm{~W}$ o consumo é baixo, mais em sistemas maiores com bombas monofásicas ou trifásicas, a economia de energia pode reduzir o custo de produção e maximizar os lucros. Segundo Luz et al. (2008) em estudos de cultivo de alface hidropônico o aumento nos intervalos das irrigações não prejudica a alteração na produção de fitomassa em intervalos de $30 \mathrm{e}$ 45 minutos e enfatiza que a diferença de tempo de funcionamento ao longo de vários ciclos de cultivo torna-se vantajosa.

Freitas et al., (2021) demonstram, entretanto que intervalos maiores ou menores podem depender da cultivar, verificando que em sistema Deep Flow Technique (DFT) cultivares de alface como a Glória e Tainá são tecnicamente viáveis em intervalos de recirculação de até 4 horas, mas a cv. Robusta apenas 2 horas. Entretanto, os critérios destes autores são embasados diretamente no tempo, enquanto que para cultivar cv. Moana é empregado um tempo variável em função da temperatura e umidade do ar, o que torna o processo de automação dinâmico.

Como a temperatura e umidade são variáveis condicionais do teste lógico. Um teste de Shapiro Wilk foi realizado para verificar a distribuição dos dados, que retornou um p-value de $2.2 \mathrm{e}^{-16}$, sendo menor que 0,05 demonstrando assim, que os dados não seguem uma distribuição normal. Portanto, ocorre variação da temperatura e umidade ao longo do dia e noite. $\mathrm{O}$ Gráfico 5 apresenta o boxplot da temperatura e umidade do ar dos dados obtidos pelo sensor DHT11, onde é possível observar não houve outliers para temperatura, ou seja, valores extremos fora dos limites interquartis, entretanto, para umidade relativa ocorre maior amplitude e variação. 
Gráfico 5. Boxplot da temperatura e umidade do ar obtidos pelo sensor DHT11 do dia 11 ao dia 29 de novembro de 2021.

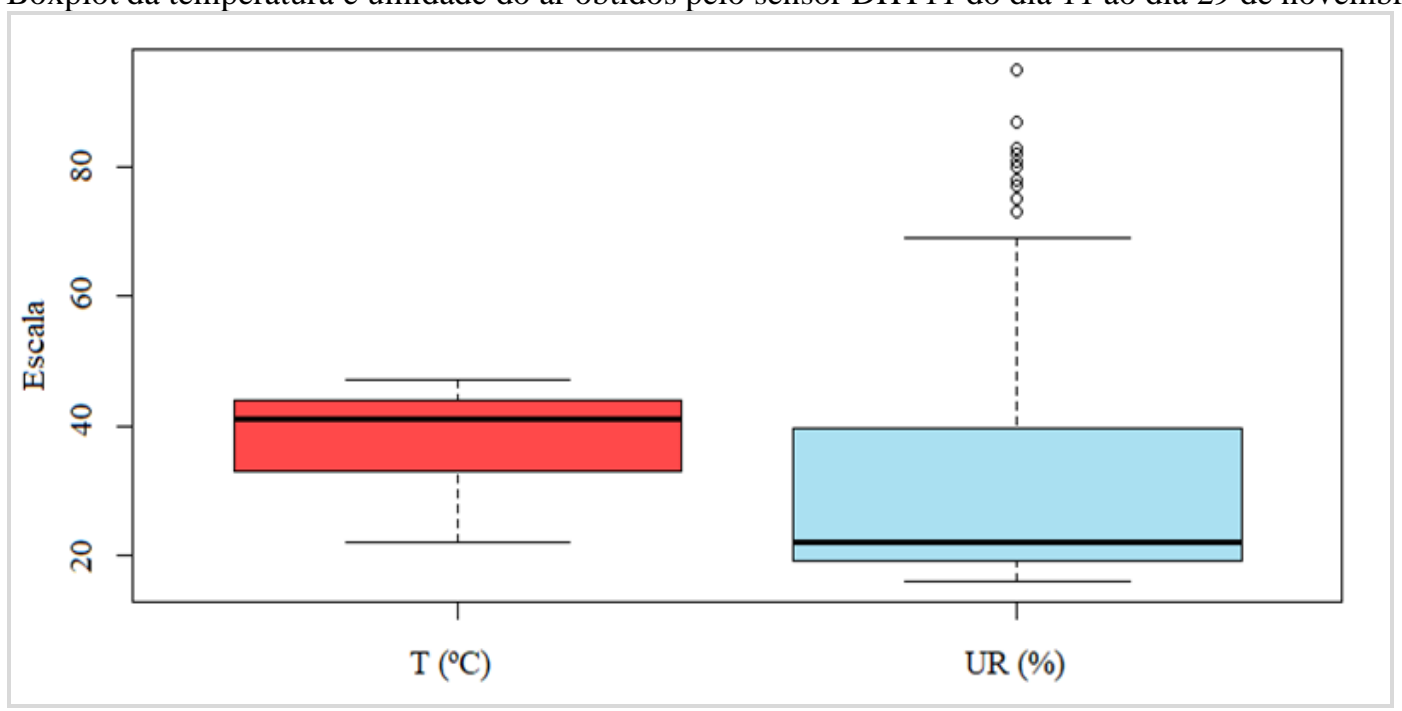

Fonte: Autores.

Essa variação de temperatura e umidade ao longo do dia, afeta diretamente os processos fisiológicos do vegetal. Segundo Taiz et al., (2017) a variação da temperatura e umidade influencia na taxa de evapotranspiração, e desse modo, na absorção de água e nutrientes da solução nutritiva. Assim, a associação desses fatores em plantas cultivadas sob estresse salino pode conduzir a inibição do crescimento ou a morte das mesmas. As temperaturas dentro e fora do viveiro divergiram, enquanto que no sensor DHT11 instalado no local do experimento a temperatura máxima foi de $47{ }^{\circ} \mathrm{C}$ e a mínima $22{ }^{\circ} \mathrm{C}$ com um CV de $16,3 \%$ e a umidade máxima $95 \%$ e a umidade mínima de $16 \%$ com um CV de 52,82\%, para a estação da UFCA a temperatura máxima foi de $35,26{ }^{\circ} \mathrm{C}$ com $\mathrm{CV}$ de $3,73 \%$, e a mínima de $22,86{ }^{\circ} \mathrm{C}$ com $\mathrm{CV}$ de $5,18 \%$ e a umidade máxima 97,30\% e mínima 26,30\% com CV 28,03\%. Demonstrando que a tela de sombreamento preta e o local do experimento com solo exposto, auxiliaram para uma elevação da temperatura. Borella et al. (2021) demonstra que no interior de viveiros com telas poliefinas pretas ou coloridas ocorre variação da temperatura e umidade do ar que dependerá da época do ano e das características da tela.

Ademais, é que as diferenças entre as máximas (Max), mínimas (Min), médias (Md) e coeficientes de variação (CV) podem também ser influências devido a precisão dos sensores e sua sensibilidade. Segundo Abrão et al., (2020) o sensor DHT11 têm uma precisão de $2{ }^{\circ} \mathrm{C}$ para temperatura e 5\% para umidade. Assim, para valores mais acurados deve-se obter sensores com maior sensibilidade. Rodrigues, Meireles e Oliveira (2021) sugerem que para obter uma maior precisão pode-se utilizar o sensor DHT22. Na Tabela 2 é apresentado o resumo da estatística básica para temperatura e umidade do ar no sensor DHT11 e da estação UFCA. 
Tabela 2. Resumo de estatística básica para temperatura e umidade no sensor DHT11 e estação da UFCA.

\begin{tabular}{lcccc}
\hline \multicolumn{1}{c}{ Descrição } & Md & Max & Min & CV $(\%)$ \\
\hline T $\left({ }^{\circ} \mathrm{C}\right)$ & 38,80 & 47,00 & 22,00 & 16,30 \\
$\mathrm{UR}(\%)$ & 30,09 & 95,00 & 16,00 & 52,82 \\
$\operatorname{TMAX}\left({ }^{\circ} \mathrm{C}\right)$ & 33,22 & 35,26 & 31,51 & 3,73 \\
$\operatorname{TMIN}\left({ }^{\circ} \mathrm{C}\right)$ & 22,86 & 25,67 & 21,32 & 5,18 \\
$\mathrm{UMIN}(\%)$ & 61,70 & 97,30 & 26,30 & 28,03 \\
\hline
\end{tabular}

Fonte: Autores.

Conforme apresentado na Tabela 2 há diferença entre os valores da estação UFCA e o sensor DHT11 instalado no Arduino. Ressalta-se que a estação da UFCA está sobre uma superfície gramada que é irrigada diariamente, e distante aproximadamente 100,00m do local do experimento. Todavia outros sensores como DHT22 que apresentam maior precisão podem ser testados, e comparados com estações meteorológicas a fim de verificar a acurácia de suas leituras.

As maiores temperaturas ocorreram entre às 13:00h e 16:00h. Com o aumento da temperatura em função do balanço de energia incidente, ocorre uma maior evapotranspiração e assim maior demanda hídrica pela cultura cultivada. De acordo com Melo et al., (2018) na cultura da alface, elevadas temperaturas podem favorecer a incidência de doenças, a termo inibição na germinação e maior dificuldade na formação da cabeça da alface americana. Entretanto, nas condições de cultivo da alface cv. Moana não foram identificadas indecências de doenças, exceto os efeitos deletérios da salinidade.

O Gráfico 6 apresenta a variação de temperatura e umidade ao longo dos dias de cultivo obtidos pelo sensor DHT11, enquanto a Gráfico 7 a variação da temperatura e umidade do ar ao longo dos dias de cultivo na estação da UFCA. Nota-se haver uma relação inversamente proporcional, onde à medida que ocorre aumento na temperatura do ar há uma redução na umidade do ar.

Gráfico 6. Variação da temperatura (T) e umidade do ar (UR) determinada pelo sensor DHT11 ao longo dos dias de cultivo dentro do viveiro.

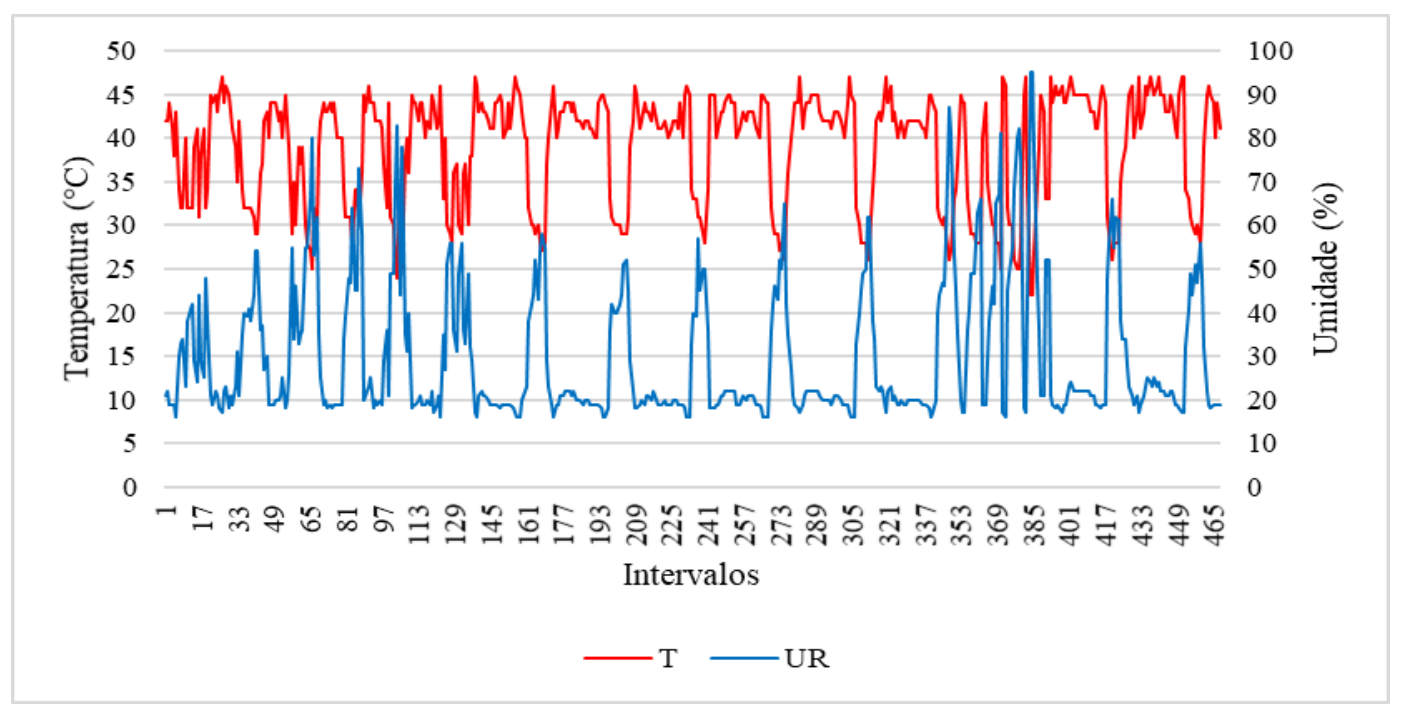

Fonte: Autores. 
Gráfico 7. Variação da temperatura (TMAX, TMIN) e umidade do ar (UR) ao longo dos dias de cultivo na estação da UFCA.

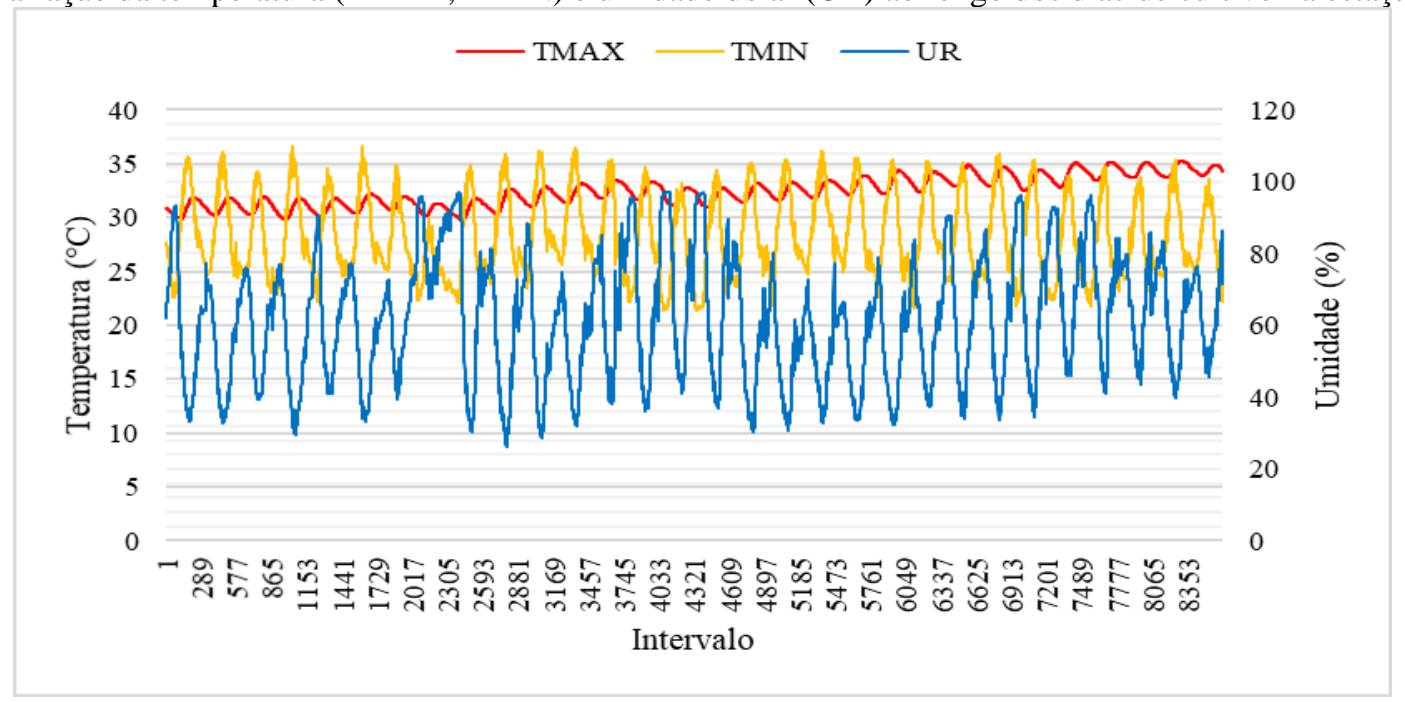

Fonte: Autores.

Essa variação e amplitude dos valores temperatura e umidade do ar, justificam desse modo o emprego do intervalo da solução de forma variável. Segundo Baron et al. (2021) em estudos com cultivo hidropônico automatizado com Arduino e sensores, LDR e umidade DHT22 concluiu que acionamento do sistema de bombeamento para recirculação da solução nutritiva, com tempo dependendo da intensidade de luz, temperatura e umidade do ar proporciona uma suavização no intervalo dos períodos de rega, evitando variações bruscas como ocorrer no sistema tradicional com timer analógico que não permite ajuste de tempos menores que 15 minutos.

Os atributos do clima como temperatura e umidade, são importantes para o gerenciamento e manejo do cultivo hidropônico, assim compreender seu comportamento é essencial para o sucesso de qualquer cultivo. Para os aspectos do clima supracitado, no que se refere aos tratamentos do cultivo da alface a variação do intervalo de circulação nutritiva condicionada por estes atributos, não afetou o desenvolvimento no tratamento T1, isso, demonstra, portanto, que esta alternativa pode ser empregada para automação de cultivos em sistemas hidropônicos. Entretanto, novos estudos são necessários para verificar se tal condição promove algum benefício para a cultura.

Portanto, mesmo nas condições semiáridas onde há estabilidade das condições climáticas, principalmente próximo ao equador com dias com duração média de luz em torno de 12 horas, a variação da temperatura ao longo do dia que ocorre em função do movimento de rotação e declinação da terra, influência na transpiração vegetal, e assim sendo, na demanda hídrica. Por conseguinte, ao aumento da transpiração vegetal na hidroponia ocorrerá uma maior absorção de nutrientes e crescimento já que estes estão dissolvidos em água (Taiz et al. 2017). Esses aspectos tornam importante o manejo do pH e da CE da solução ao longo do cultivo, principalmente quando se usa águas com maiores teores de sais, visto que estas contribuem para uma inibição do crescimento por stress ou morte do vegetal.

A alteração do pH ao longo do tempo na solução nutritiva ocorre em decorrência da absorção de nutrientes e liberação de íons $\mathrm{H}^{+}$, nesse sentido ocorre uma tendência natural para acidificação da solução nutritiva (Dias, 2019). O que fez necessário a aplicação $\mathrm{NaOH}$ para regulação do $\mathrm{pH}$ para os níveis ideais. A Tabela 3 apresenta o pH médio dos tratamentos e o coeficiente de variação, enquanto que no Gráfico 8 a variação do pH ao longo do cultivo. 
Tabela 3. pH médio e CV para os diferentes tratamentos.

\begin{tabular}{|c|c|c|c|c|}
\hline Tratamento & $\mathrm{Md}$ & Max & Min & $\mathrm{CV}(\%)$ \\
\hline $\mathrm{T} 1$ & 5,62 & 6,45 & 4,94 & 6,40 \\
\hline $\mathrm{T} 2$ & 5,95 & 6,50 & 5,22 & 5,30 \\
\hline $\mathrm{T} 3$ & 5,83 & 6,20 & 5,45 & 3,67 \\
\hline $\mathrm{T} 4$ & 5,91 & 6,05 & 5,08 & 5,96 \\
\hline T5 & 5,82 & 6,71 & 5,11 & 6,28 \\
\hline
\end{tabular}

Fonte: Autores.

Gráfico 8. Variação do pH ao longo dos dias de cultivo na bancada NFT para os tratamentos.

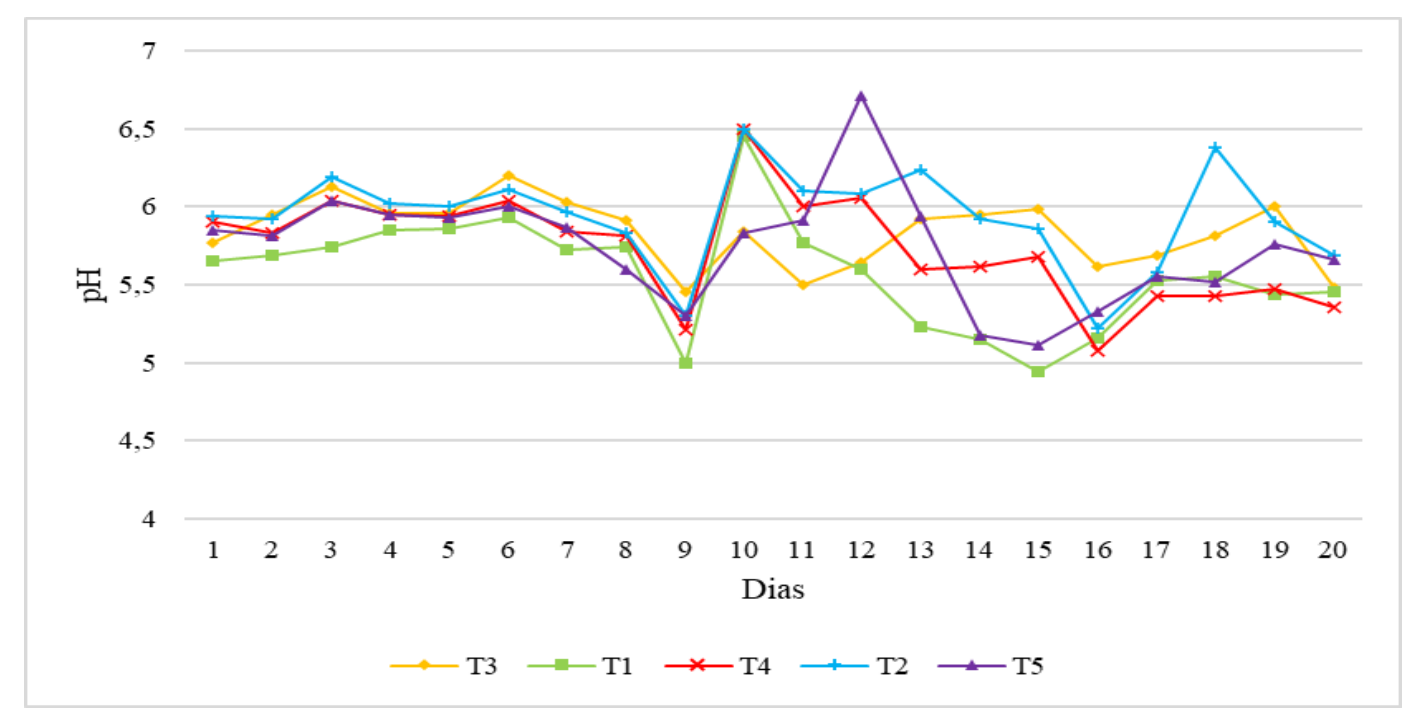

Fonte: Autores.

Os baixos coeficientes de variação do $\mathrm{pH}$ foram conseguidos através do monitoramento diário da solução, tal acompanhamento objetiva garantir que nenhum outro aspecto infira sobre o desenvolvimento da alface a não ser o sistema de automação e os níveis de salinidade. O controle do pH é essencial para garantir a disponibilidade de nutrientes. Ao longo do cultivo o pH foi mantido dentro da faixa ideal de 5,5 a 6,5 (Guimarães, Trindade \& Lage, 2020). Deste modo, as condições nutricionais restritivas ao desenvolvimento foram controladas.

A CE da solução é um indicador da absorção de nutrientes pela cultura, entretanto, em condições salinas o teor de sal da água pode mascarar essa referência. À medida que as plantas se desenvolvem caso esses limites mínimos nutricionais estabelecidos sejam atingidos, estes devem ser restaurados (Monteiro Filho et al. 2018). A Tabela 4 apresenta o CE médio e o seu coeficiente de variação, no Gráfico 9 é possível verificar a variação da condutividade elétrica da solução ao longo dos dias de cultivo para cada tratamento. 
Tabela 4. CE médio e CV para os diferentes tratamentos.

\begin{tabular}{llllc}
\hline Tratamento & Md & Max & Min & CV (\%) \\
\hline T1 & 1,52 & 1,57 & 1,32 & 5,72 \\
T2 & 1,96 & 2,14 & 1,80 & 3,97 \\
T3 & 2,51 & 2,74 & 2,10 & 7,87 \\
T4 & 2,95 & 3,07 & 2,60 & 3,54 \\
T5 & 3,47 & 3,70 & 3,24 & 3,37 \\
\hline
\end{tabular}

Fonte: Autores.

Gráfico 9. Variação da CE ao longo dos dias de cultivo na bancada NFT para os tratamentos.

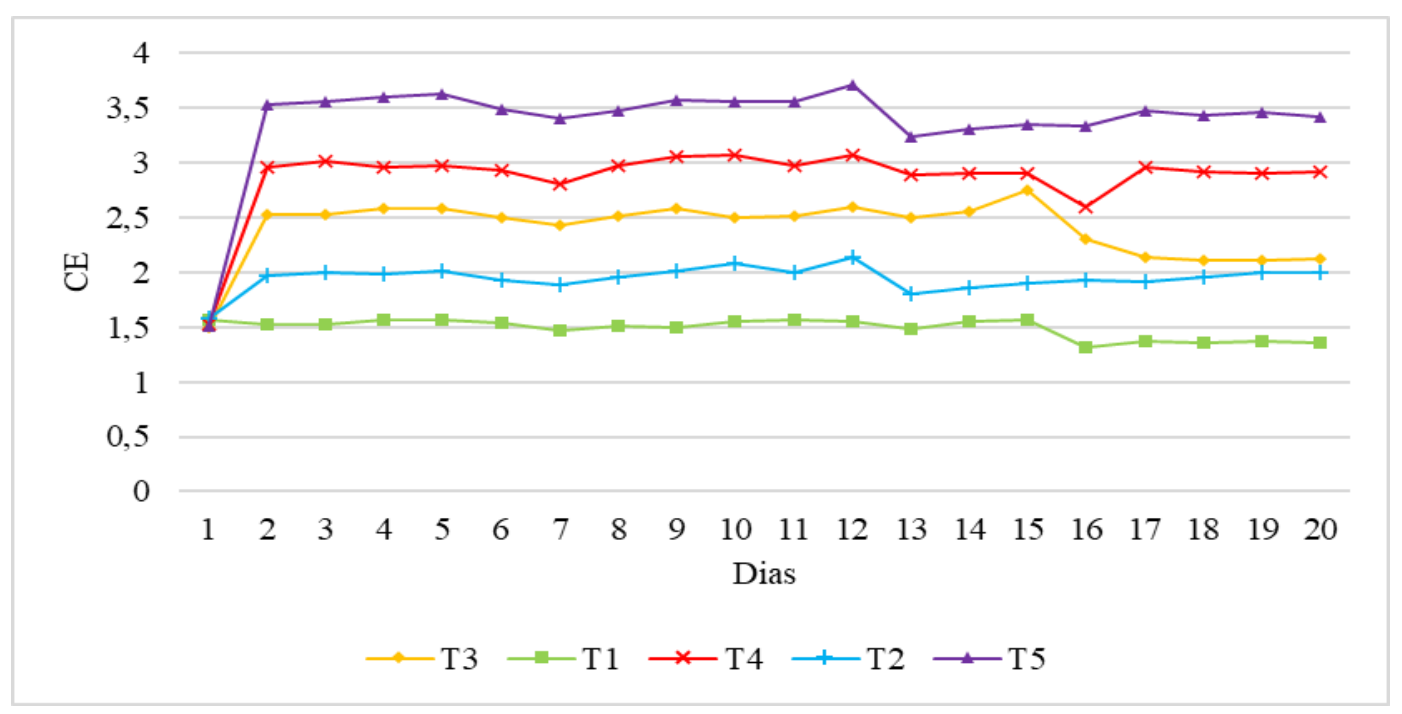

Fonte: Autores.

Para CE também apresentou um baixo CV, isso demonstra que os níveis de condutividade para cada tratamento foram mantidos dentro dos limites estabelecidos. O controle da CE é essencial para o monitoramento da absorção de nutrientes e sua reposição. Segundo Bezerra Neto (2017) a reposição desses nutrientes, entretanto, não é fácil comumente utiliza-se a condutividade elétrica como indicador. Por isso é importante, como especificado por Taiz et al. (2017) garantir a disponibilidade adequada de nutrientes na solução nutritiva, para que durante o processo de desenvolvimento a solução tenha os nutrientes necessários de forma suficiente a suportar o desenvolvimento vegetal sem haver déficit.

Outro aspecto a ser considerado é a temperatura da solução que também é um fator importante para o desenvolvimento da alface. Para auxiliar esse controle os reservatórios de solução nutritivas foram enterrados, o que contribuiu para normalizar a temperatura da solução nutritiva dos diferentes tratamentos.

"Os reservatórios devem ficar longe do caminho de pessoas e animais, de preferência, enterrado no solo em lugar sombreado ou com uma cobertura de telha, palha, etc. (regiões de clima quente). A borda do reservatório deve estar no mínimo $20 \mathrm{~cm}$ acima do nível do solo e, cimentado ao seu redor, a fim de se evitar possíveis contaminações (solo, água de chuva etc.)." (Cometti et al. 2019, p.43). 
Na Tabela 5 observa-se a média e o CV das temperaturas registradas nos tanques de cada tratamento às 8:00h, enquanto que, no Gráfico 10 a variação da temperatura da solução ao longo dos dias de cultivo.

Tabela 5. Temperatura média da solução e CV para os diferentes tratamentos às 8:00h.

\begin{tabular}{lcccc}
\hline Tratamento & Md & Max & Min & CV (\%) \\
\hline T1 & 27,00 & 30,50 & 25,70 & 4,11 \\
T2 & 27,00 & 28,80 & 25,50 & 3,15 \\
T3 & 28,52 & 33,10 & 26,80 & 4,64 \\
T4 & 28,90 & 25,60 & 3,42 \\
T5 & 26,80 & 28,90 & 25,50 & 3,64 \\
\hline
\end{tabular}

Fonte: Autores.

Gráfico 10. Variação da temperatura nos tanques de solução nutritiva às 8:00h ao longo dos dias de cultivo.

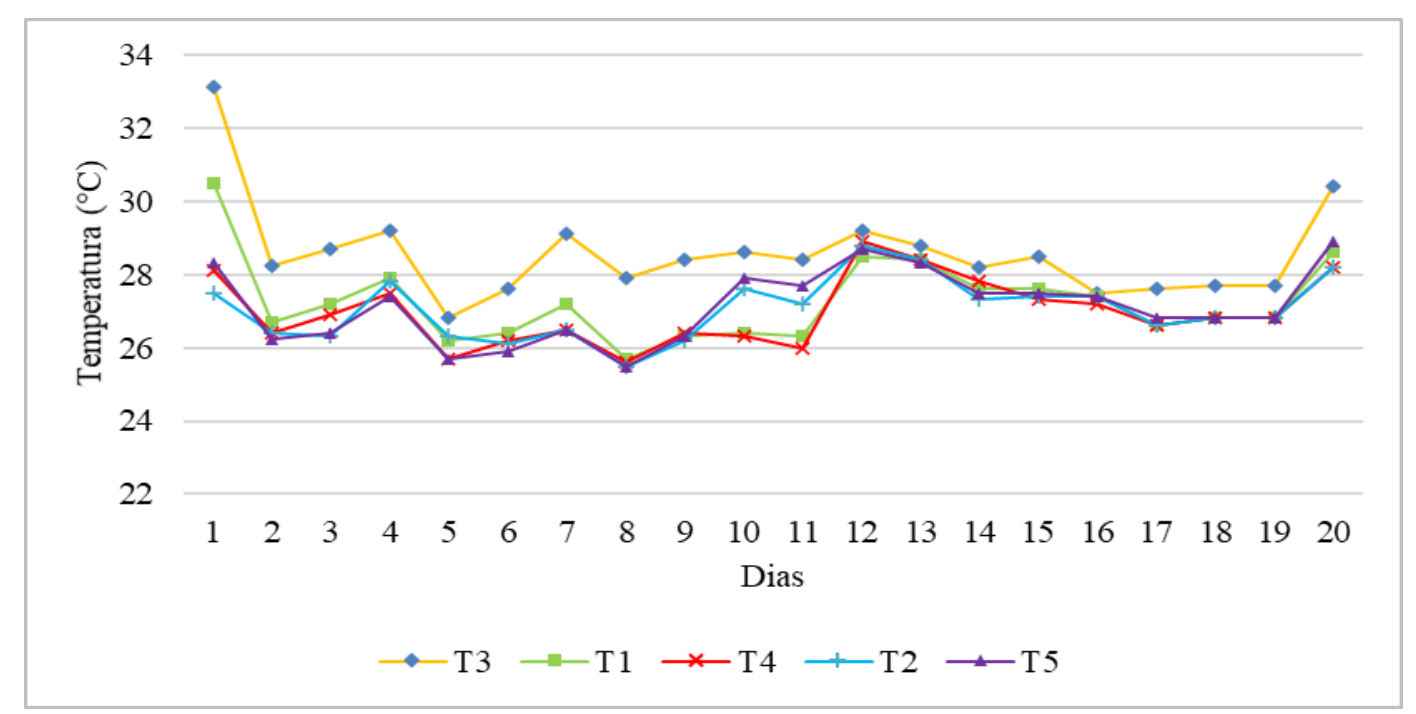

Fonte: Autores.

O baixo coeficiente de variação assim como a temperatura média, denotam que não houve grandes variações de temperatura entre os tratamentos. Dessa forma, com valores médios próximos de temperatura e controle do $\mathrm{pH}$ e $\mathrm{CE}$ da solução, garante-se que o vegetal apenas teve como fator diferencial à salinidade entre os tratamentos associado aos intervalos de recirculação da solução.

As alfaces transplantadas para as bancadas em seus respectivos tratamentos, apresentavam de 4 a 5 folhas bem definidas, não apresentando qualquer injúria ou indicador de ataque de pragas. Mudas maiores, podem ser utilizadas como relata Martins (2021) que produziu mudas de maior porte com 6 a 8 folhas com diferentes cultivares de alface.

A utilização de mudas uniformes é essencial para garantir que nos diferentes tratamentos não houve interferência em decorrência da desuniformidade das plantas. A boa uniformidade foi conseguida devido ao sistema de produção de mudas desenvolvido por ascensão capilar, que apesar de simples e barato apresentou-se eficiente. A Figura 3 apresenta as mudas de alface sete dias após o transplante quando ainda não tinha iniciado os efeitos deletérios da salinidade. 
Figura 3. Mudas de alface no dia 18 de novembro de 2021 com 7 dias após o transplante.

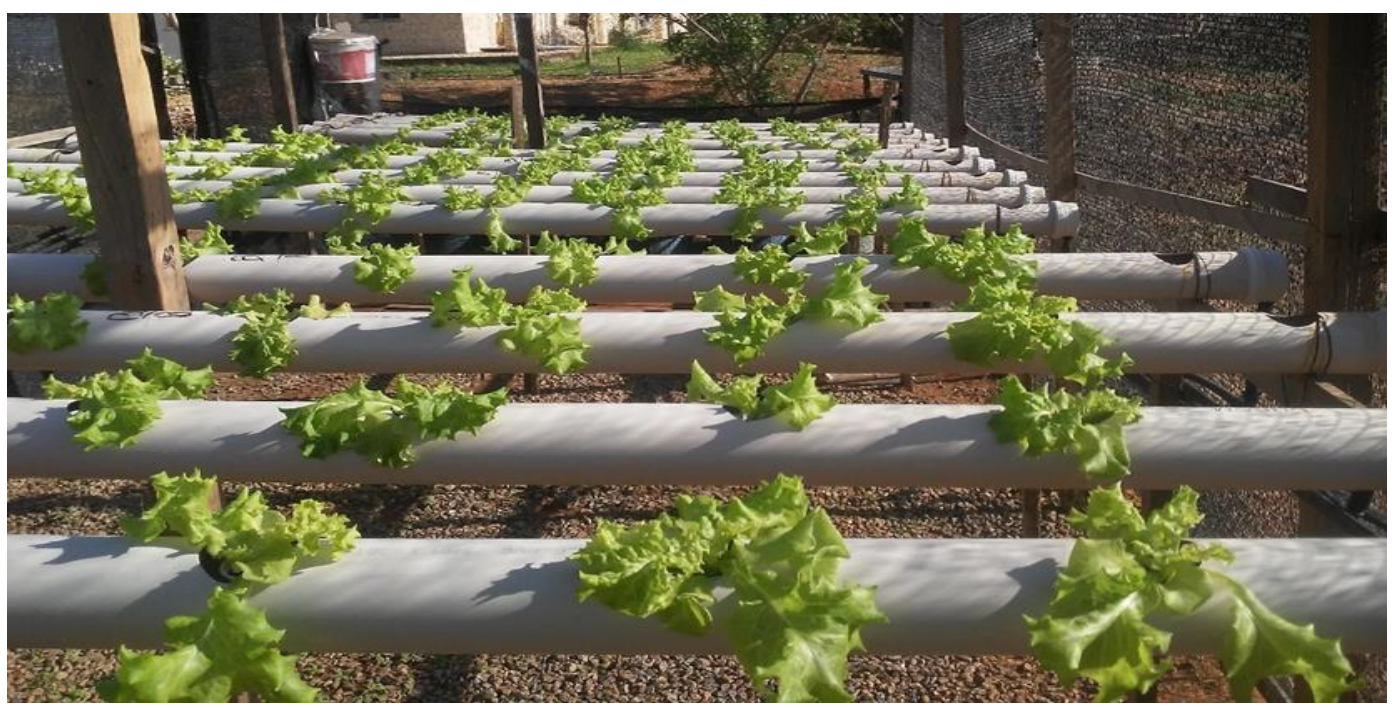

Fonte: Autores.

Durante os dez dias iniciais de desenvolvimento, a alface não apresentou diferença significativa a nível de 5\% de probabilidade para o número de folha (NF) e diâmetro caulinar (DC). Possivelmente os efeitos da salinidade foram atenuados, em detrimento das condições de clima mais brandas de temperatura e umidade do ar nesse período. A Tabela 6 apresenta a síntese da ANAVA para o NF e DC da alface, enquanto que, no Gráfico 11 é possível observar os seus valores médios.

Tabela 6. Resumo da análise de variância para o número de folhas (NF) e diâmetro caulinar (DC) para os diferentes tratamentos do dia 20/11/2021.

\begin{tabular}{lccc}
\hline \multicolumn{1}{r}{ Fonte Variação } & Grau liberdade & & Quadrado médio \\
\cline { 3 - 4 } & & $\mathrm{NF}$ & $0,0094^{\mathrm{ns}}$ \\
\hline Tratamento & 4 & $0,640^{\mathrm{ns}}$ & $0,0134^{\mathrm{ns}}$ \\
Blocos & 4 & $2,240^{\mathrm{ns}}$ & 0,0106 \\
Resíduo & 16 & 0,965 & \\
Total & 24 & & 23,24 \\
\hline CV $(\%)$ & & 16,48 & \\
\hline
\end{tabular}

*Diferiram entre si pelo teste F ao nível de 0,05 de significância NS Não diferiram entre si ao nível de 0,05 de significância pelo teste F; CV $\%$ : coeficiente de variação. Fonte: Autores. 
Gráfico 11. Valores médios do NF e DC da ANAVA do dia 20/11/2021.

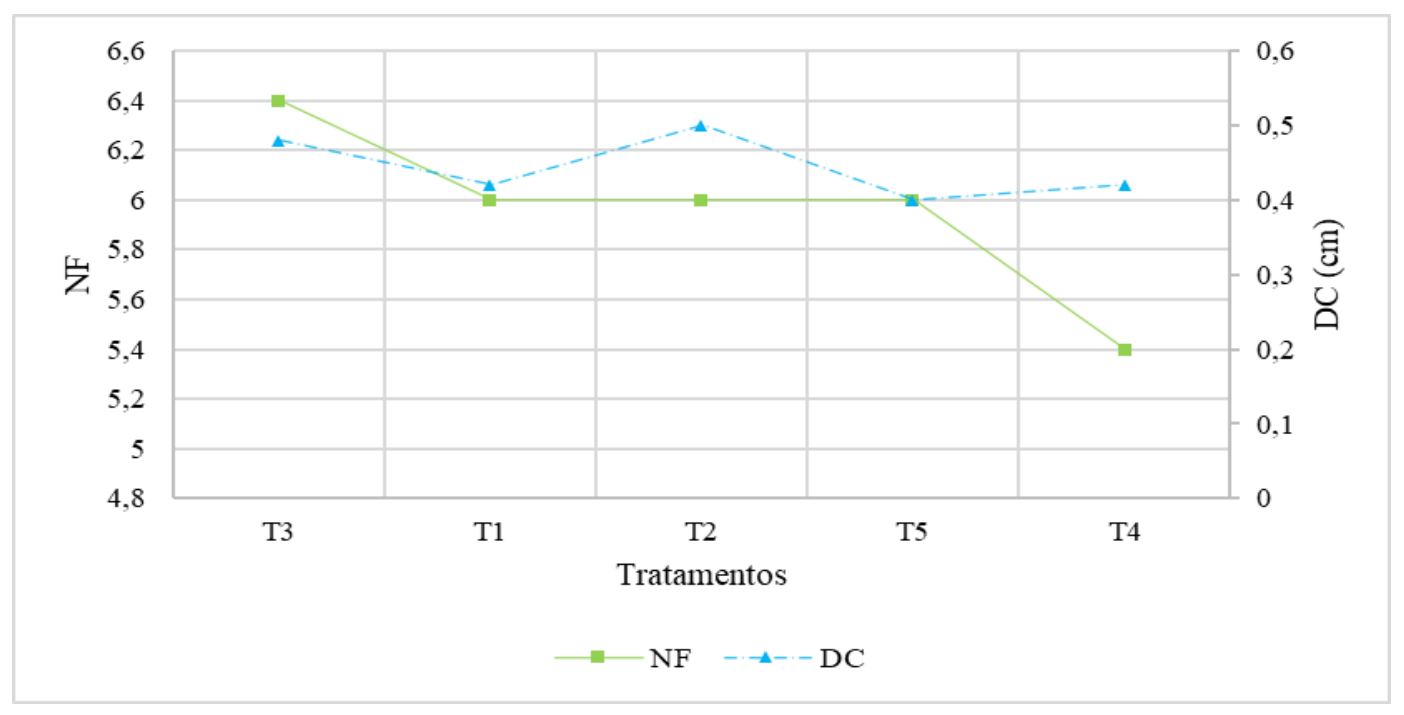

Fonte: Autores.

Silva et al. (2017) demonstra os efeitos da salinidade no crescimento do vegetal e relata que o diâmetro do caule é um dos parâmetros mais sensíveis à salinidade. Mas durante os primeiros dias de cultivo, não se verificou diferença significativa no DC. Por outro lado, a ANAVA do NF e DC do dia 29 de novembro de 2021, demonstrou haver diferença significativa a nível de $5 \%$ de probabilidade entre tratamentos, na Tabela 7 é apresentado o resumo da análise.

Tabela 7 - Resumo da análise de variância para o número de folhas (NF) e diâmetro caulinar (DC) para os diferentes tratamentos do dia 29/11/2021.

\begin{tabular}{lccc}
\hline \multirow{2}{*}{ Fonte variação } & Grau liberdade & & Quadrado médio \\
\cline { 3 - 4 } & & NF & DC \\
\hline Tratamento & 4 & $60,726^{* *}$ & $0,2348^{* *}$ \\
Blocos & 4 & $0,805^{\mathrm{ns}}$ & $0,0141^{\mathrm{ns}}$ \\
Resíduo & 16 & 0,781 & 0,01189 \\
Total & 24 & & 23,37 \\
\hline CV $(\%)$ & & 20,52 & \\
\hline
\end{tabular}

*Diferiram entre si pelo teste F ao nível de 0,05 de significância NS Não diferiram entre si ao nível de 0,05 de significância pelo teste F; CV $\%$ : coeficiente de variação. Fonte: Autores.

Conforme apresentado na Tabela 7, houve diferença significativa para o número de folhas e diâmetro entre os tratamentos, não havendo diferença entre blocos. O fato de não haver diferença entre os blocos, pode ocorrer porque no sistema NFT existe uma maior homogeneidade na aplicação da solução, justificando não haver diferença significativa entre blocos.

Para os tratamentos o CV do NF foi de $20,52 \%$ enquanto que para o diâmetro caulinar 23,37\%, sendo considerado baixo. No Gráfico 12 é apresentado os valores médios do desdobramento pelo teste de Tukey. 
Gráfico 12. Valores médios do NF e DC (cm) da ANAVA do dia 29 de novembro de 2021.

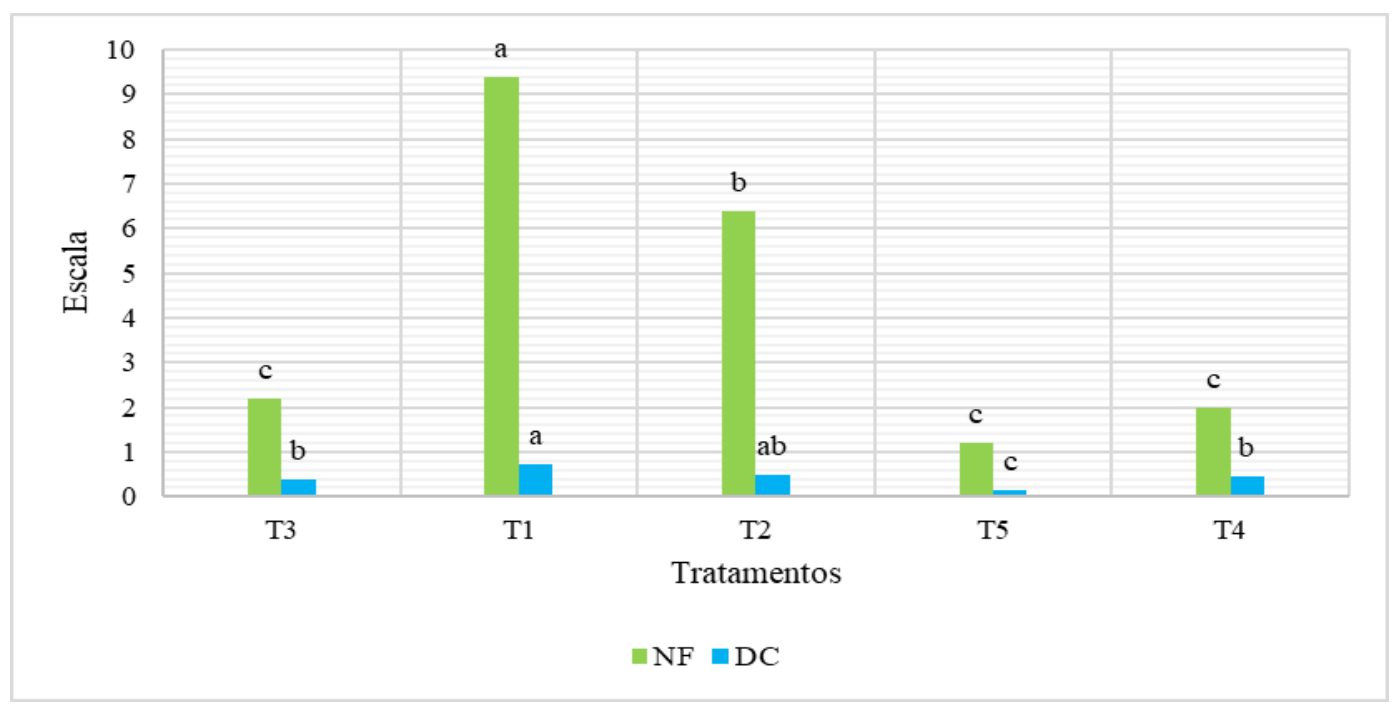

Fonte: Autores.

Conforme o desdobramento das médias para o teste de Tukey, nota-se haver diferença do NF entre os tratamentos T1 e T2, entretanto, para o DC não ocorre diferença. O que permite inferir que a salinidade teve maior efeito sobre a parte aérea do vegetal. Os tratamentos T3, T4 e T5 apresentaram valores médios iguais para NF e o tratamento T4 e T3 apresentaram valores equivalentes para o diâmetro, sendo inferiores aos tratamentos T1 e T2.

Silva et al. (2017) encontrou valores semelhantes 25 dias após o transplante com diâmetro caulinar variando 0,60 a $1,00 \mathrm{~cm}$ e um número de folhas de 4 a 8 do maior ao menor nível de salinidade e concluiu que os níveis crescentes de salinidade afetam o desenvolvimento da alface crespa. Do mesmo modo, Silva et al. (2018) verificou que sob níveis de salinidade menores a alface apresenta maior produtividade assim como maior acúmulo de umidade em suas folhas.

Taiz et al. (2017) relata que os efeitos da salinidade se assemelham aos efeitos do déficit hídrico e que os efeitos primários são: redução do potencial hídrico, desidratação celular, citotoxicidade iônica. A Figura 4 apresenta o efeito da salinidade nos diferentes tratamentos nos dias 29 de novembro de 2021.

Figura 4. Efeito da salinidade nos diferentes tratamentos no dia 29 de novembro de 2021 com 18 dias após o transplante.

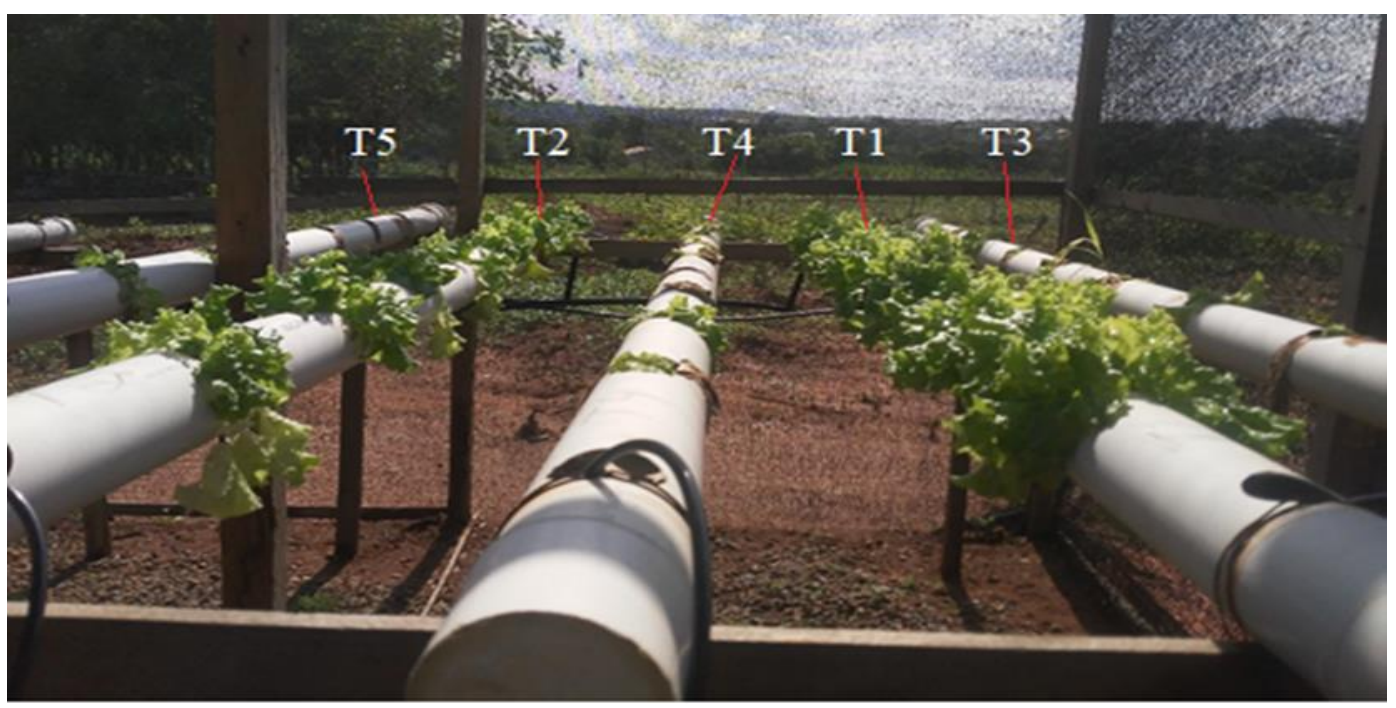

Fonte: Autores. 
Observa-se que as plantas dos tratamentos T3, T4 e T5 não se demonstram viáveis para comercialização, visto que devido às altas temperaturas do período e ao estresse salino, suas folhas sofreram necrose por conta dos efeitos deletérios da salinidade e temperatura. Portanto, sugere-se para futuras pesquisas testar o cultivo no semiárido sob condições mais amenas de temperatura e umidade e diluição da solução nutritiva, tal como verificar se no período chuvoso se é possível cultivar sob uma salinidade superior.

Bezerra Neto (2017) e Paulus et al. (2012) demonstram ser importante não usar águas com condutividade elétrica muito elevada, a fim de evitar que com a dissolução dos sais a condutividade elétrica não se eleve ao ponto de limitar ou inibir o desenvolvimento da cultura. Isso fica evidenciado nos tratamentos T3, T4 e T5 onde a associação das altas temperaturas, baixa umidade e estresse salino fez com que as plantas definham após alguns dias de cultivo.

Observa-se que apesar dos níveis restritivos ao cultivo de alface, estes podem não se aplicar a outra cultura. Silva et al. (2016) por exemplo cultivou coentro (Coriandrum sativum L.) utilizando a formulação proposta por Furlani et al. (1998) e verificou um bom desenvolvimento da cultura com água salobra a níveis de 4,1 dS m-1, e sugere ser viável uma recirculação da solução nutritiva a cada 8 horas em técnica de inundação "Deep Flow Technique (DFT)" em tubos de PVC de 75 mm.

O resultado dos atributos morfológicos da alface da ANAVA para a MFT, MFR e MFF demonstra que para MFF e MFT há diferença significativa entre os tratamentos T1 e T2, conforme pode ser observado na Tabela 8 e o Gráfico 13 que apresenta o resumo do desdobramento para o Teste de Tukey.

Tabela 8. Resumo da análise de variância para massa fresca total (MFT), massa fresca das raízes (MFR) e massa fresca das folhas (MFF) para os diferentes tratamentos do dia 30/11/2021.

\begin{tabular}{lcccc}
\hline \multirow{2}{*}{ Fonte variação } & Grau liberdade & \multicolumn{3}{c}{ Quadrado médio } \\
\cline { 3 - 5 } & & MFT & MFR & MFF \\
\hline Tratamento & 4 & $1218,2^{*}$ & $93,621^{\text {ns }}$ & $659,39^{*}$ \\
Blocos & 4 & $2,20^{\text {ns }}$ & $0,865^{\text {ns }}$ & $5,23^{\text {ns }}$ \\
Resíduo & 16 & 6,61 & 0,971 & 5,29 \\
Total & 24 & & & \\
\hline $\mathrm{CV}(\%)$ & & 23,88 & 31,19 & 30,21 \\
\hline
\end{tabular}

*Diferiram entre si pelo teste F ao nível de 0,05 de significância NS Não diferiram entre si ao nível de 0,05 de significância pelo teste F; CV $\%$ : coeficiente de variação. Fonte: Autores. 
Gráfico 13. Médias dos tratamentos T1 e T2 para o desdobramento pelo teste de Tukey 43 dias após o plantio.

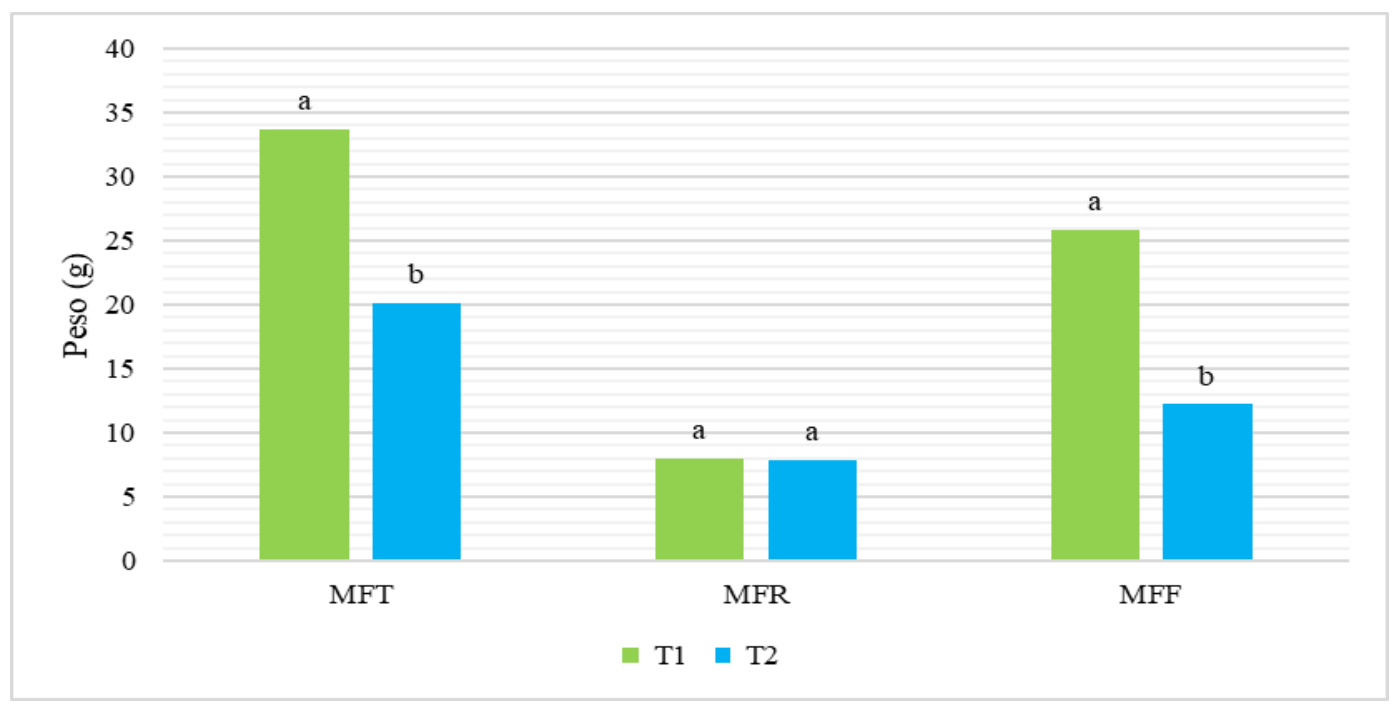

Fonte: Autores.

Os coeficientes de variação para MFT, MFR e MFF foram de 23,88, 32,39 e 30,21 \% respectivamente, o que demonstra a variabilidade das características morfológicas da alface cv. Moana. Conforme apresentado na Gráfico 13 aos 43 dias após o transplante há uma redução da MFF da alface cv. Moana e MFT em função da variação de 0,5 $\mathrm{dS} \mathrm{m}^{-1}$ de condutividade. Xavier et al. (2021) encontrou resultado semelhante para o efeito da salinidade no desenvolvimento da alface, verificando um decrescimento na MFF para plantas com 56 dias após a semeadura, para o nível de 1,9 $\mathrm{dS} \mathrm{m}^{-1}$ obteve uma MFF de $160 \mathrm{~g}$ planta e 4,9 $\mathrm{dS} \mathrm{m}^{-1}$ uma MFF $100 \mathrm{~g}$ planta, enquanto o NF foi de 16 e 10 respectivamente, em condições de temperatura máxima e mínima de $40{ }^{\circ} \mathrm{C}$ e $20^{\circ} \mathrm{C}$ respectivamente.

Posto isto, foi possível analisar a dinâmica da automação em detrimento da variação da temperatura e umidade do ar no cultivo da alface cv. Moana sob os diferentes níveis de salinidade. Além de constatar que essa dinâmica pode contribuir para aspectos de redução de energia, demonstrando assim que a variação do intervalo de automação pelas condições locais é possível. Outro ponto, é que a pesquisa abre brechas para associação de outros sensores, é a criação de novos sistemas de automação onde as condições locais controlam a recirculação de água e nutrientes. Portanto, verificou-se que nos aspectos avaliados a automação do sistema não é obrigatoriamente em um tempo fixo, é que esta pode ser variável e dependerá das condições locais e cultura avaliada.

Ademais, foi verificado os efeitos deletérios da salinidade sob a alface cultivada nas condições ambientais do experimento, e constatado que níveis de salinidade muito altos inviabilizam o cultivo, assim, deve-se testar soluções diluídas, já que com o aumento da transpiração ocorre uma maior absorção de água e sais minerais, desse modo, uma solução com menor CE pode ser mais viável para o semiárido.

\section{Considerações Finais}

O crescimento inicial da alface no semiárido é possível sob as mais diversas condições de temperatura, umidade e salinidade desde que adotado as técnicas de manejo e estruturas adequadas, devendo-se verificar, portanto, o ciclo completo do vegetal. Foi constatado que o cultivo de alface para condições de alta temperatura e baixa umidade somente é viável para níveis de CE inferiores a $2 \mathrm{dS} \mathrm{m}^{-1}$ e que a salinidade restringe o desenvolvimento da alface podendo ocasionar a sua morte. Outro ponto, e que para o sucesso em cultivo hidropônico o manejo do $\mathrm{pH}$ e CE da solução nutritiva é essencial para o desenvolvimento pleno da cultura. 
Por fim, o sistema de automação com Arduino Uno demonstra-se promissor e sem restrições e traz o benefício de acoplar sensores e armazenar dados, além da recirculação da solução nutritiva pela variação da umidade e temperatura do ar, entretanto novas pesquisas devem ser conduzidas.

Para futuras pesquisas, deve-se verificar se sob diferentes intervalos há alguma vantagem para desenvolvimento do vegetal. Outro ponto, a ser estudado e se com uma redução no teor de sais da formulação nutritiva, pode ser benéfica para a produção hidropônica em condições semiáridas, onde a maior temperaturas e menores umidades. Pode-se também verificar a viabilidade de um sistema de automação conectado a internet, para acesso dos dados e acionamento remotamente. Em relação à salinidade, recomenda-se testar outras cultivares e culturas, assim como, o seu consórcio. Por fim, este estudo abre a possibilidade de desenvolvimento de sistemas de automação dinâmicos e não estáticos, não apenas para cultura da alface, mas para diversas outras culturas em cultivo hidropônico

\section{Agradecimentos}

Os autores agradecem a Universidade Federal do Cariri (UFCA), a Coordenação de Aperfeiçoamento de Pessoal de Nível Superior (CAPES), ao Programa Institucional de Bolsas de Iniciação Cientifica (PIBIC/UFCA) e ao Programa Institucional de Bolsas de Iniciação em Desenvolvimento Tecnológico (PIBITI/UFCA).

\section{Referências}

Abrão, B., Luginieski, L., Silva, R. A., Betim, L. M., \& Silva, C. M. (2020). Automation and data control system with artificial lighting for plant grow. Revista ecknoeng (21), 1-23. http://www.cescage.com.br/revistas/index.php/RTE/article/view/819/pdf.

Araújo, J. C. (2012). Recursos hídricos em regiões semiáridas. In: Gheyi, H. R., Paz, V. P. S., Medeiros, S. S. \& Galvão, C. O.(ed). Recursos Hídricos em regiões semiáridas: estudos e aplicações (1. ed, Cap. 2, pp. 30-39). INSA.

Baron, L. C., Nogueira, C. E. C., Siqueira, J. A. C., \& Miotto, A. (2021). Desenvolvimento e avaliação da viabilidade técnica de dispositivos para automação hidropônica. Revista universidade Unigranrio, 8(1), 188-210. http://publicacoes.unigranrio.edu.br/index.php/amp/article/view/6689/3443.

Bernardo, S., Mantovani, E. C., Silva, D. D., \& Soares, A. A. (2019). Manual de Irrigação (9a ed.). UFV.

Bezerra Neto, E. (2017). Cadernos do Semiárido: Hidroponia. (6. ed). Pernambuco, PE: CREA. http://www.ipa.br/novo/pdf/cadernos-do-semiarido/6--hidroponia.pdf\#: :text=As\%C3\%A9rie\%20Cadernos\%20do\%20Semi\%C3\%A1rido\%20traz\%20neste\%20seu\%20sexto,s\%C3\%A3o\%20fornecidos\%20por\% 20meio $\% 20 \mathrm{de} \% 20$ solu $\%$ C3\%A7\%C3\%B5es\%20nutritivas\%20balanceadas.

Blat, S. F., Sanchez, S. V., Araújo, J. A. C., \& Bolonhezi, D. (2011). Desempenho de cultivares de alface crespa em dois ambientes de cultivo em sistema hidropônico. Horticultura brasileira, 19(1), 135-138. https://www.scielo.br/j/hb/a/hv837SXCdV44PfFSSR5xwYv/?format=pdf\&lang=pt.

Borella, D. R., Souza, A. P., Silva, K. N. C., Santos, L. L. M., Ximenes, E. S. O. C. \& Anjos, A. M. (2021). Dinâmica das estimativas da temperatura e umidade do ar em viveiros protegidos com diferentes sombreamentos. Revista Pesquisas Agrárias e Ambientais, 9(1), 62-75. https://periodicoscientificos.ufmt.br/ojs/index.php/nativa/article/view/11437/7940.

Brito, L. T. L., Pereira, L. A., \& Melo, R. F. (2009). Disponibilidade hídrica subterrânea. EMBRAPA. http://www.agencia.cnptia.embrapa.br/gestor/bioma_caatinga/arvore/CONT000g5twggzi02wx5ok01edq5s9s9b6a3.html.

Cometti, N. N., Genuncio, G. C., \& Zonta, E. (2019). Hidroponia para técnicos IFPB.

Costa Filho, W. D., Galvão, M. J. T. G., Lima, J. B., \& Leal, O. (1998). Noções básicas sobre poços tubulares.: CPRM.

Dias, R. H. (2019). Desempenho de cultivares de alface em sistema semi-hidropônico fertirrigadas com soluções nutritivas salinizadas. Mossoró, RN: UFERSA. https://repositorio.ufersa.edu.br/bitstream/prefix/3278/2/RayssaHD_MONO.pdf.

Domingos, A. S. (2019). Sistema de Monitoramento de cultivo hidropônico. https://wiki.sj.ifsc.edu.br/images/f/fb/Projeto_de_TCC_Alline_Silva_Domingos.pdf.

Freitas, F. T. O., Soares, T. M., Silva, M. G., \& Rafael, M. R. F. (2021). Cultivo de alface sob intervalo de recirculação das soluções nutritivas em sistema hidropônico utilizando águas salobras. Revista Irriga, 1(1), 67-96. https://200.145.140.50/index.php/irriga/article/view/4253/2817.

Furlani, P. R. (1998). Instruções para o cultivo de hortaliças de folhas pela técnica de hidroponia NFT. IAC.

Furlani, P. R., Silveira, L. C. P., Bolonhenzi. D., \& Faquin, V. (1999). Cultivo hidropônico de plantas. IAC.

Gama, D. C., \& Jesus, J. B. (2019). Principais solos da região semiárida do brasil favoráveis ao cultivo do Eucalyptus L' Heritier. Revista Biofix Scientifc Journal, 5(2), 214-221. https://revistas.ufpr.br/biofix/article/view/70968/40421. 
Guimarães, A. Z., Trindade, E. N. O., \& Lage, F. C. (2020). Fazendas urbanas aquaponia e hidroponia: sistemas para uma produção independente. Revista exatamente-newton, (1), 107-12. http://revistas.newtonpaiva.br/revista-exatamente/wp-content/uploads/2020/12/REVISTA-EXATAMENTE-NEWTON-N.1ART9.pdf.

Júnior, L. M., Ferreira, M. A., \& Canato, R. L. C. (2020). Microcontrolador e sensores aplicados na automação de horta hidropônica. Interciência e Sociedade, 5(2), 356-357. http://revista.francomontoro.com.br/intercienciaesociedade/article/view/165/121.

Lima, M. T. V., Meireles, A. C. M., Oliveira, C. W., \& Nascimento, N. T.B. (2017). Koppen-Geiger and Thornthwaite Climatic classification for the metropolitan region of the Cariri, Ceará. Revista Geama, 3(3). http://www.journals.ufrpe.br/index.php/geama/article/download/1500/1319.

Luz, G. L., Medeiros, S. L. P., Mafron, P. A., Borcione, E., Müller, L., Amaral, A. D., \& Morais, K. P. (2008). Consumo de energia elétrica e produção de alface hidropônica com três intervalos entre irrigações. Revista Ciência Rural, 38(13), .815-818. https://www.scielo.br/j/cr/a/9G4D3TbDM89kYbMn4mvyPby/?lang=pt\&format=pdf.

Martins, T. S. (2021). Desempenho Agronômico de cultivares de alface em sistema hidropônico no município de Uruçúi-PI. IFPB.

Melo, D. F., Lima, S. C., Guimarães, R. F. B., Furtado, D. A., \& Nascimento, R. (2018). Influência da estufa hidropônica no crescimento de diferentes cultivares de alface crespa (Lactuca Sativa L.). In Congresso Técnico Científico de Engenharia e Agronomia. Maceió, AL: CONTECC. Maceió, AL: CONTECC. https://www.confea.org.br/sites/default/files/antigos/contecc2018/agronomia/143_idehncddcdaclsl.pdf.

Monteiro Filho, A. F., Azevedo, C. A. V., Azevedo, M. R. Q. A., Fernandes, J. D., Silva, C. R.., \& Fernandes, P. D. (2018). Monitoring, calibration and maintenance of optimized nutrient solutions in curly lettuce (Lactuca sativa, L.) hydroponic cultivation. Revista Australian Journal of Crop Science, 12(4), 572-582. https://www.cropj.com/filho_12_4_2018_572_582.pdf.

Paulus, D. (2008). Produção, Qualidade, parâmetros fisiológicos e bioquímicos de alface sob hidroponia com águas salinas. Universidade de São Paulo.

Paulus, D., Paulus, E., Nava, G. A., \& Moura, C. A. (2012). Crescimento, consumo hídrico e composição mineral de alface cultivada em hidroponia com águas salinas. Revista Ceres, 1(59), 110-117. http://www.ceres.ufv.br/ojs/index.php/ceres/article/view/3701/1607\#.

Rodrigues, L. G., Meireles, A. C. M., \& Oliveira, C. W. (2021). Desenvolvimento de software e mini estação meteorológica com arduino uno para monitoramento da umidade do solo, temperatura e umidade do ar. In Inovagri Meeting Virtual e XXX CONIRD. Fortaleza, CE: INOVAGRI. https://icolibri.com.br/meeting2021/public/biblioteca/inovagri-meeting-2021/RES0170004.

Santos, J. W., \& Gheyi, H. R. (2003). Estatística experimental aplicada. Marcone.

Silva, A. L., Nascimento, M. N., Tanan, T. T., Oliveira, U. C., \& Lima, J. C. (2017). Efeito da salinidade da água de irrigação na produção da alface crespa. Revista centro científico conhecer, 14(26), 328-338. http://www.conhecer.org.br/enciclop/2017b/agrar/Efeito\%20da\%20salinidade.pdf.

Silva, D. A. O., Santos, W. M., Silva, T. S. S., Fernandes, S. P., Carneiro, P. T., \& Santos, C. G. (2018). Desempenho da alface (Lactuca Sativa L.) submetida a diferentes níveis de salinidade da água de irrigação. Revista Ambiental, 10 (3), 32-42. https://periodicosuneal.emnuvens.com.br/ambientale/article/view/56/55.

Silva, M. G., Soares, T. M., Gheyi, H. R., Oliveira, I. S., Filho, J. A.S, \& Carmo, F. F. (2016). Frequency of recirculation of nutrient solution in hydroponic cultivation of coriander with brackish water. Revista Brasileira de Engenharia Agrícola e Ambiental, 20(5), 447-454. https://doi.org/10.1590/18071929/agriambi.v20n5p447-454.

Soares, T. M, Silva, E. F. F., Duarte, S. N., Melo, R. F., Jorge, C. A., \& Bonfim-Silva, E, M. (2007). Produção de Alface utilizando águas salinas em sistema hidropônico. Revista Irriga, 12(2), 235-248. https://www.ufrb.edu.br/neas/images/Artigos_NEAS/2007_14.

Taiz, L., Zeiger, E., Moller, I. M., \& Murphy, A. (2017). Fisiologia e Desenvolvimento Vegetal. (6a ed). Artmed, 2017. https://grupos.moodle.ufsc.br/pluginfile.php/474835/mod_resource/content/0/Fisiologia\%20e\%20desenvolvimento\%20vegetal\%20-

$\% 20$ Zair $\% 206 \%$ C2\%AAed.pdf.

Xavier, J. F., Azevedo, C. A. V., Azevedo, M. R. Q. A., Sales, J. C. R., Oliveira, N. C., \& Fernandes, J. D. (2021). Soluções nutritivas salinizadas com cloreto de sódio no cultivo da alface crespa em sistema hidropônico. Revista Research, Society and Development, $10(14)$, e515101420437. https://rsdjournal.org/index.php/rsd/article/view/20437/19846.

Ximenes, L. F., Silva, M. S. L., Brito, L. T. L. (2019). Tecnologias de convivência com semiárido. Embrapa. 